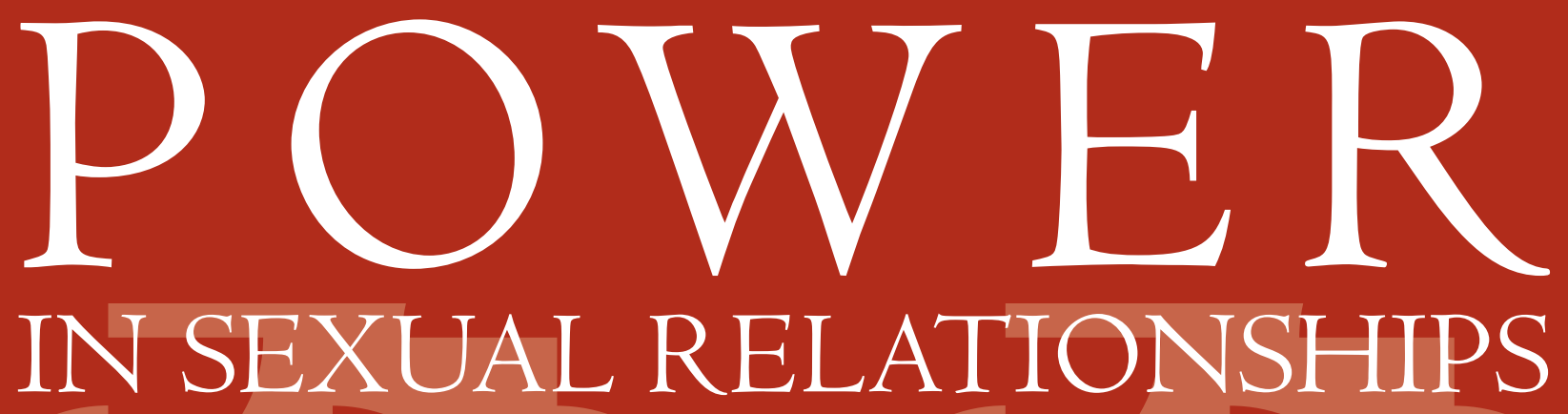

An opening dialogue among reproductive bealtb professionals 


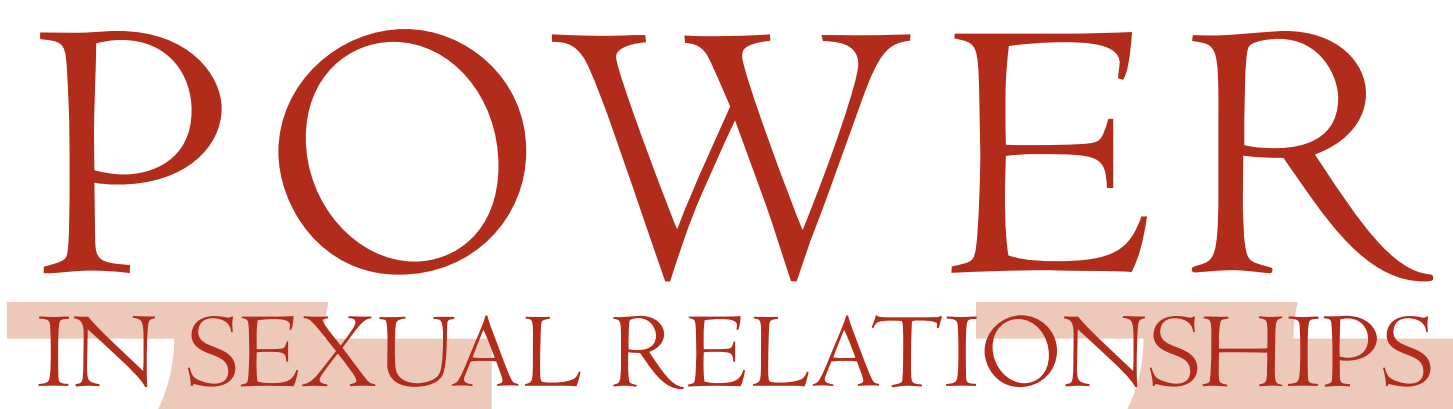

An opening dialogue among reproductive bealtb professionals

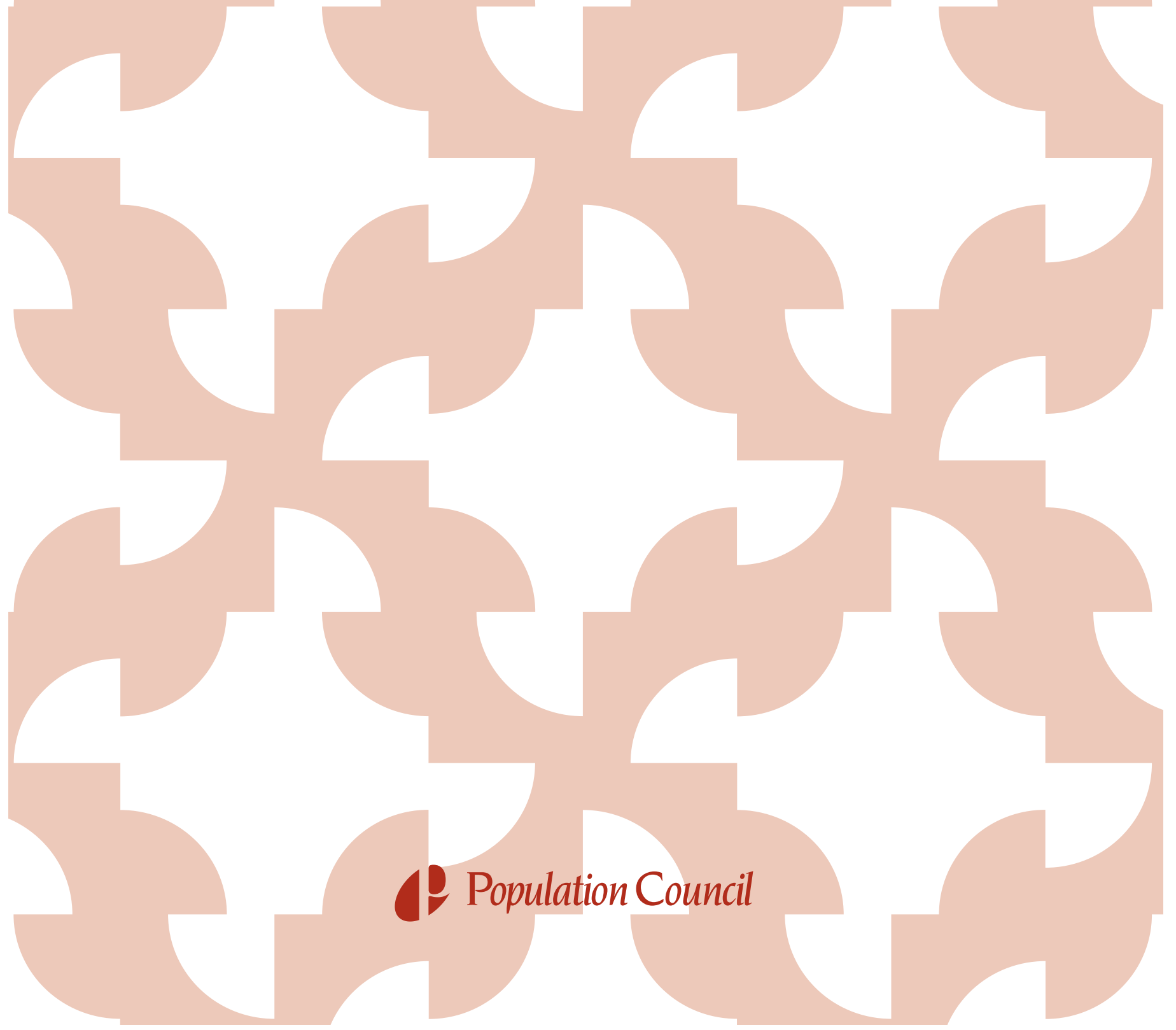




\section{(2) Population Council}

One Dag Hammarskjold Plaza

New York, New York 10017

telephone: 001 212-339-0500

fax: 001 212-755-6052

e-mail: pubinfo@popcouncil.org

www.popcouncil.org

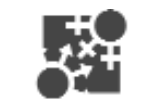

I G WG

United States Agency for

International Development

1300 Pennsylvania Avenue, NW

G/PHN/POP/PE3.6.142B

Washington, DC 20523

telephone: 001 202-712-0662

fax: 001 202-216-3046

e-mail: IGWG@usaid.gov

The Population Council is an international, nonprofit, nongovernmental institution that seeks to improve the well-being and reproductive health of current and future generations around the world and to help achieve a humane, equitable, and sustainable balance between people and resources. The Council conducts biomedical, social science, and public health research and helps build research capacities in developing countries. Established in 1952, the Council is governed by an international board of trustees. Its New York headquarters supports a global network of regional and country offices.

Established in 1997, the Interagency Gender Working Group (IGWG) is a network of nongovernmental organizations, including the United States Agency for International Development (USAID) Cooperating Agencies, and the Center for Population, Health, and Nutrition (PHN) of the USAID. IGWG promotes gender equity within PHN programs, in order to improve Reproductive Health/HIV/AIDS outcomes and foster sustainable development.

Copyright (C) 2001 by The Population Council, Inc.

Any part of this publication may be photocopied without permission from the authors or publisher, provided that publication credit is given and that copies are distributed free. Any commercial reproduction requires prior written permission from the Population Council.

Funding for this document was provided by USAID. The views expressed by the authors do not necessarily reflect the views or policies of USAID. 


\section{CONTENTS}

Preface $\quad$ v

Acknowledgments vii

Power in Sexual Relationships: What Is the Evidence? $\quad 1$

Field-Based Efforts: Service Delivery 14

Field-Based Efforts: Community 19

Field-Based Efforts: Socialization 26

Comments from the Community of

Donors and Implementing Agencies 31

Looking to the Future: Working Groups 43

$\begin{array}{ll}\text { Closing Remarks } & 48\end{array}$

Appendix: Meeting Participants 51 



\section{PREFACE}

For most of its history, the population and public health field skirted issues of sexuality and avoided acknowledging the role of differential power in sexual relationships between men and women. Silence on these matters was excused before the HIV/AIDS epidemic by beliefs that these relationships were "private," that acts between partners were fully voluntary, that people would be reticent to discuss their sexual behavior and health, and finally, that even if intervention were considered desirable on public health or other grounds, bringing about changes in sexual relationships would be too difficult.

The 1994 Cairo International Conference on Population and Development and the 1995 Beijing Women's Conference publicly ended the silence by focusing attention on how gender influences sexual relations and reproductive health decisionmaking. Participants at the Beijing Conference adopted a resolution condemning sexual coercion. Sponsored by women from both modern and traditional cultures, the resolution served as an open declaration that much sexual activity for many women was neither safe, nor voluntary, nor, dare it be voiced, pleasurable.

Women and women's health advocates have not been the only ones concerned about communication, equality, and power in sexual relationships. Public health and social development professionals and many men began to voice concerns that male gender roles were also limiting men's lives-leading to unequal and risky sexual relationships for them-and fostering many negative outcomes for society, such as high rates of sexually transmitted infections and sexual violence.

While the role of power in sexual relationships has in recent years been acknowledged, this understanding has largely lacked practical expression in the reproductive health field. The discussions summarized in the following report indicate that gender-based power inequalities hinder communication between partners, limit the ability of individuals and couples to talk about or achieve desired child spacing and family size goals, limit effective use of reproductive health services, undercut men's and women's attainment of sexual health and pleasure, and increase substantially their vulnerability to HIV/AIDS and other sexually transmitted infections.

International efforts to reduce the impact of AIDS have increasingly highlighted unequal power in sexual relationships as a vital factor in the spreading epidemic, especially among adolescents and young adults. In some parts of the world where the epidemic is in full swing, the ratio between female and male infection rates among those aged $15-24$ is 8 to 1 . As Paul Delay said in the course of this meeting, HIV has become "essentially a girls' epidemic driven by male behavior."

This report summarizes the proceedings of a meeting, co-sponsored by the Population Council and USAID's Interagency Gender Working Group's Men and Reproductive Health Subcommittee, that responded to an increasing ground- 
swell of interest. Many organizations in attendance believed it was imperative to open a dialogue on power in sexual relationships, indeed on sexuality itself, to affirm what we know and urge a continuing learning process fed by diagnostic research and carefully observed experimental programs.

The participation at this meeting was eclectic by design: reproductive health professionals concerned with this subject matter have long felt that they need the advice and perspective of those with a much more in-depth knowledge of sexuality per setheir own perspective is too confined to conventional views. Further, we sought the counsel of those with a sociological perspective on how boys and girls and men and women construct their sexual identities. Finally, we cannot move the debate much further without improved measurement tools - some drawn from distant fields - to define and view meaningful dimensions of power in sexual relationships and document the ability of interventions to change them.

This meeting was a call to action. Among the 141 people who attended, there was a unified sense that inequality in sexual relationships is a vital issue in public health and social development. Par-

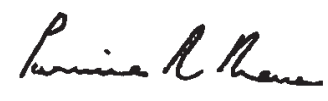

Purnima Mane, Population Council

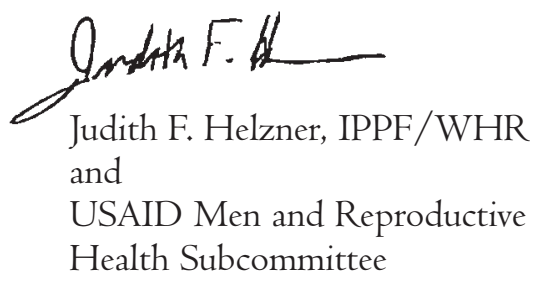

ticipants pointed to the need for greater efforts in multiple areas-continuing theoretical work, descriptive psychological and sociological analysis, and operations research to name a few. Evidence presented indicated that such changes in behavior and attitudes are possible. We heard about progress made in eight field-based interventions, all providing valuable information and one overwhelming messagemany men and women in less-developed countries are ready to discuss the issue of inequality in sexual relationships and believe changes are in order. We heard from members of donor and implementing agencies that they have taken note and that sexuality and power in sexual relationships has become a central theme in some of their programs. And, significantly, we heard from those leading the fight against HIV/AIDS. For this community, changing the dynamics between men and women and within sexual relationships and "empowering" the weaker partner (usually, but not always, a woman) have become vital points of intervention.

We thus hope this report will inspire commitment within the reproductive health community to respond to this call for action.
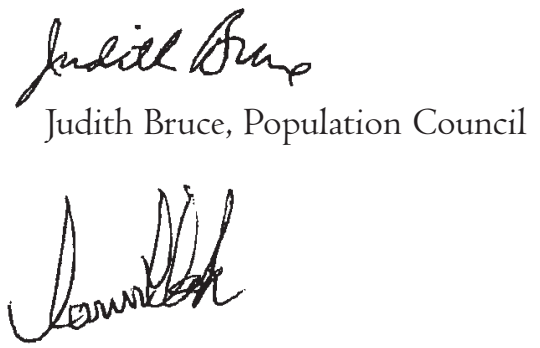

Sam Clark, PATH

and

USAID Men and Reproductive Health Subcommittee 


\section{ACKNOWLEDGMENTS}

The meeting on power in sexual relationships, convened in Washington, DC, 1-2 March 2001, was a joint effort of the Population Council's New York and DC offices and the USAID Interagency Gender Working Group's Men and Reproductive Health Subcommittee. We are grateful to the Subcommittee for providing substantive and financial support to the meeting and for assistance in publishing this report. We are also grateful to the Swedish International Development Cooperation Agency (SIDA) for providing leadership on this agenda and financial support to the meeting.

We thank Ann Leonard for persisting with this topic and keeping it high on the Population Council's agenda. She and Judith Helzner, of the Subcommittee, spearheaded this meeting as representatives of their respective organizations. Other colleagues from the Council who put tireless effort into conceptualizing and planning this meeting included Sandra Bjegovic, Judith Bruce, Erica Chong, Rachel Goldberg, Michelle Gray, Purnima Mane, Carey Meyers, Julie Pulerwitz, Naomi Rutenberg, and Ellen Weiss. Thanks also to Sarah Douglass, Emily Knox, Eva Roca, and Melissa VanderKooi from the
Council's Washington, DC office for providing logistical support on the meeting days. PATH kindly helped us to secure the meeting space.

We also thank Ann Blanc for taking up the challenge of preparing the stateof-the-art review of the literature on power in sexual relationships. This review served as a starting point for our discussions throughout the meeting. We had an illustrious and dedicated group of speakers- too long to be listed here, but named in the report-who led us through two highly stimulating days.

Rachel Goldberg conceptualized the report, wrote each summary, and oversaw its production. However, this final product represents the collaborative work of many: Michal Avni, Susan Bloodworth, Sam Clark, Margaret Greene, Rebeca Quiroga, and Karin Ringheim acted as notetakers. Debbie Rogow offered invaluable editing, reviewer comments, and text contributions. Jennifer Blum, Judith Bruce, Erica Chong, Judith Helzner, Ann Leonard, Purnima Mane, Carey Meyers, Suellen Miller, and Monica Rocha provided insightful reviewer comments and guidance. And Sandra Bjegovic provided technical assistance throughout the writing process. 



\section{POWER IN SEXUAL RELATIONSHIPS: WHAT IS THE EVIDENCE?}

Opening remarks

(Margaret Neuse)

The opening session was chaired by Margaret Neuse, Director of USAID's Office of Population. Neuse reflected on the historical reliance on certain contraceptive methods over others within the population and family planning field. Those methods that have been favored not only provide the most effective protection from pregnancy, but also require little or no involvement of partners in use or decisionmaking. As a result, few programs have experience discussing method use in the context of sexual relations.

Neuse noted the growing recognition in the family planning field that decisionmaking on sexual matters, including the use of contraception, is complex and often involves many actors other than the woman herself (or the man in the case of vasectomy). There have been some successful efforts at male involvement, but these are relatively small-scale and often not well evaluated. She argued for dedicating sufficient resources to learning, measuring, and assessing issues of power in sexual relationships, and how it relates to use of contraception and associated decisions.

The spread of HIV/AIDS, she noted, demands a great acceleration of the learning and application process.
Condom use, the one effective means to prevent transmission, requires communication and working out some of the sexual dynamics and power relationships. Those in the field now have a dual responsibility - to keep a central focus on family planning and reproductive health, and to define and assume our role in fighting the epidemic. Neuse concluded by stating that an understanding of power in sexual relations is crucial for both tasks.

\section{The effect of power in sexual} relationships on reproductive and sexual health: An examination of the evidence (Ann Blanc)

The first session centered on an overview paper reviewing research in the area of power and sexual relationships, which the Population Council had commissioned Ann Blanc ${ }^{1}$ to prepare for this meeting. Blanc addressed three tasks:

1. Review what has been learned to date about the role of gender-based power in sexual relationships in determining reproductive and sexual health outcomes;

2. Draw lessons from clinic and community-based interventions that address power; and

\footnotetext{
${ }^{1}$ Ann Blanc was formerly with the Demographic and Health Surveys (DHS) program and is currently president of her own demographic consulting firm.
} 
3. Highlight gaps in knowledge and priority areas for future interventions and research.

Blanc told the group that she was struck by the magnitude of what is already known. She reviewed principally the family planning literature, which focuses on heterosexual unions; however, she also drew insights from work in other aspects of reproductive health, including HIV/AIDS. Below are some highlights.

\section{Thinking about power}

Blanc highlighted a distinction between "power to" (the ability to act) and "power over" (the ability to assert wishes and goals even in the face of opposition from another). She argued that what is important for purposes of examining the role of power in sexual relationships is not the absolute power of either member of a couple, but the comparative influence of members relative to each other. She added that gender inequities operate within the context of other types of power imbalances_-such as those based on race, wealth, or age- and interact with them.

What are the consequences of unequal power?

Characteristics at the individual, couple, family, and community level influence both the balance of power and the extent to which individuals have access to and use reproductive health services. Genderbased power relations can have a direct effect on the ability of partners to acquire information, to make decisions, and to take action related to their reproductive health, safety, and well-being.

\section{Reproductive decisionmaking}

The relationship between reproductive decisionmaking and gender-based power is complex. Often, a woman and her partner may not agree on the desirability of pregnancy or the use of contraception. In spite of much research, however, the evidence regarding whose opinion carries more weight in reproductive decisionmaking cannot be generalized across settings, and even within the same setting the evidence has not always been consistent.

Studies have shown that although the majority of men say they approve of family planning in the abstract, their own partner's use of contraception often raises concerns and resistance. Concerns expressed by men include fear that they will lose their role as head of the family, that their partners will become promiscuous or adulterous, and that they will be ridiculed by other members of the community. While men are often the primary decisionmakers in family planning, they may leave the implementation of their decisions to their partners. This attitude is reinforced by services that tend to be geared exclusively toward women.

Women who perceive that their husbands will not support the decision to use contraception may use a method surreptitiously. Openly using contraception in defiance of a partner's real or perceived wishes is difficult for many women, especially those who are eco- 
nomically dependent on their partners and those whose partners can threaten them with separation, divorce, or violence. However, surreptitious use has its costs as well: going against a husband's will is viewed as uncharacteristic of being a good wife, fear of being found out is a constant burden, and seeking medical help for problems or side effects is awkward.

Use of reproductive bealth services

Power differentials directly influence women's access to and utilization of reproductive health services. One of the most concrete ways this occurs is through men's control of their wives' financial resources or mobility. This does not necessarily mean that men purposely deny women health care. Instead, their ignorance about women's reproductive health may lead them to have incorrect assumptions and make uninformed decisions.

Men's sexual bealth and pleasure

Unequal power relations can have a detrimental influence on men's sexual health as well. The limited information that is available on this topic suggests that both physical and psychosexual problems are common among men. Yet men's concerns about appearing powerful and in control can discourage them from discussing sexual health problems with their partners or others, including service providers.

\section{Gender-based violence}

Gender-based violence has a multitude of negative effects on women's reproductive and sexual health. In addition to the immediate injury, the damage to women's physical and mental well-being can include depression, anxiety, gynecological problems, and pregnancy complications (including fetal loss). Sexual violence may result in unwanted pregnancy and sexually transmitted infections (STIs). Even fear of abuse may inhibit women from refusing unwanted sex or from raising the issue of contraception or condom use, leaving many women and girls at risk of unwanted pregnancy and STIs.

Vulnerability to HIV/AIDS and sexually transmitted infections

Quantitative studies have demonstrated that increased power among women is often associated with increased condom use. However, because women are often expected to be ignorant and passive about sexual matters, it is difficult for them to be informed about risk reduction strategies. Even among women and girls who are informed, unequal power reduces their ability to negotiate disease protection, to express their concerns about sexual fidelity, and to say no to sex. Economic dependence on men further reinforces their vulnerability: it increases the likelihood that they will submit to unsafe sex as an insurance policy against abandonment or in exchange for money or favors. In cultures where virginity is highly valued, young women may be coerced by older men into having sex, or may turn to practices such as anal sex that preserve their virginity but place them at increased risk for STIs. 
Norms about masculinity and its association with power, self-reliance, and risk-taking also contribute to men's vulnerability to HIV/AIDS. Multiple sexual relationships for men are condoned, or at least not condemned, in many societies. This leads some men to pursue many partners, including commercial sex workers, in spite of being aware of the risks. In addition, the expectation that men will be self-reliant discourages them from seeking information about sex or protection from disease, and encourages the denial of risk.

What have interventions that address power demonstrated?

In addition to what we have learned from research that addresses partnership issues (i.e., that male involvement often promotes reproductive health and that both women and men seek a more active role for male partners), there are a number of lessons from interventions that directly consider questions of gender power.

Men who want to participate face barriers Although both women and men generally welcome greater involvement by male partners in reproductive health matters, men who attempt to become involved in women's or children's health may face barriers that arise from norms about appropriate gender roles. Other men and family members may react negatively. Service systems may also be unwelcoming. Facilities may not have space for male partners to wait, and health workers may refuse to allow them access to labor and obstetrical wards or to examination rooms. In some studies, men have reported that they have been treated rudely or made to feel that they have no legitimate reason to be there.

Clients want to discuss issues of sexuality

There is significant evidence that clients are usually relieved and happy to be asked about their sexual lives by concerned providers. That men and women are willing to talk about sexual matters, however, is not to say that they necessarily find it easy. Indeed, it appears that intensive training of providers (on issues such as sexuality, gender, and power) and continuous support following training are crucial for effective discussions with clients.

\section{Intervention models}

Blanc categorized intervention approaches that have acknowledged or attempted to influence power relations along a continuum that ranges from the most basic to the most ambitious:

- Providing clients with information that explicitly recognizes the role of partners in reproductive health choices and outcomes;

- Improving the exchange of information between clients and providers and addressing the context of sexual relations;

- Promoting peer education and communication;

- Providing the client's partner with information and inviting him to participate in services; 
- Integrating the dynamics of sexual relations into services for men; and

- Seeking to change community norms and practices.

\section{Programmatic challenges}

Those who have attempted to develop programs that influence power relations in sexual relationships have frequently faced the criticism that gender relations are a component of "culture," which is seen as impermeable to-or inappropriate for-external intervention. Nevertheless, some programs that have sensitively addressed deeply embedded traditional practices and beliefs have met with success.

One dilemma for programs is how to honor the desires of women or men who wish to use family planning in spite of their partner's opposition. Providers need to recognize that legitimate disagreements will exist within couples, and the relative weight given to the needs of individuals versus the needs of the couple must be addressed with careful consideration of the rights and responsibilities of each partner.

In many settings, female family members provide assistance, information, and care for pregnant and recently delivered women. It is important that there not be any weakening of positive traditional supports. In some settings, the extended family's vested interest in children can be a strong incentive to continue childbearing, even if the couple prefers to limit their family size. Programs that endeavor to manipulate power relations within couples need to acknowledge the full range of actors who participate in decisionmaking related to reproductive and sexual health.

The discomfort of clinic and other program staff with the discussion of sensitive topics such as sex and sexual violence is inevitable. Programs that have incorporated training on such topics have encountered some initial resistance by staff, embarrassment, and some personal biases that can inhibit counseling. Yet many programs have also found that provider discomfort can be overcome, although it may take some time and may require ongoing support for staff.

\section{Methodological challenges}

One of the deficiencies of research to date is the small number of rigorous quantitative models that specify the link between gender-based power relations and sexual and reproductive health outcomes. Power itself is rarely measured; thus if a desirable outcome occurs, it is often not possible to attribute it to a change in power relations. Studies that link an intervention to changes in power, and then to a specific health outcome, are greatly needed.

Such research has no doubt been inhibited by the lack of a commonly accepted definition of power and the absence of useful and practical measures of power relations. A number of methodological approaches to the measurement of power have been under- 
taken, including measures of the relative say of partners in decisionmaking, locus of control, women's autonomy, and women's empowerment. These measures have been shown to be related to specific outcomes in some settings. It is not clear yet whether any of these measures could be employed outside of the specific setting in which they were devised.

\section{Major ethical challenges}

As noted above, family planning programs unavoidably confront the issue of partners who disagree about the use of contraception or of particular methods, and the desires of women to use contraception secretly. In the area of STI diagnosis and treatment, partner notification programs must consider questions of confidentiality and protection of clients. Similarly, screening clients for gender-based violence and providing adequate support for those who report violence require weighing the potential harm versus the benefits that can be achieved.

\section{Future priorities}

Develop interventions that directly address the balance of power in sexual relationships Most important (and challenging) are the development, implementation, and evaluation of interventions that directly and intentionally address the balance of power within sexual relationships. Such interventions must include baseline and follow-up measures of power relations, difficult as they will be to develop and validate.
Diversify, scale up, and document interventions that address power More documentation from a range of settings and with a variety of intervention types is crucial. As studies accumulate, the evidence base describing what is feasible and what is acceptable under different circumstances can be built. Evidence in adapting and scaling up promising interventions is also lacking.

Tackle partnership issues at the level of the individual and the couple

There is tremendous need to evaluate the relative effectiveness of providing services for couples versus for individuals, and much scope for learning about the sequencing of this (perhaps beginning with the individual client and moving on to the couple). Crucial in the work ahead is finding programmatic means that make use of health service interaction to improve communication between partners. Finally, we must test different kinds of communication packages to find out which are most effective in neutralizing gender-based power imbalances.

\section{Intervene and conduct research in} multiple arenas

In spite of the recognition that power in sexual relationships is the result of processes operating at multiple levels, it is unusual for programs to introduce multilevel interventions. Even more pressing is the need for research that examines gender-based power and its impact at multiple levels (e.g., individual, family, community). 
Identify an approach to power that is specific to adolescent sexual relationships

Adolescents are constructing their sexual identities, becoming independent of their parents, and are particularly susceptible to peer pressure; as such, they are a key audience for interventions that attempt to address power in sexual relationships. Yet, as numerous observers have noted, such interventions must be based not upon the experience and perspectives we derive from observing adults, but upon the distinct realities of adolescent sexual partnerships. Even among adolescent girls there are at least two subgroups-unmarried girls who may be occasionally sexually active and are generally trying to avoid pregnancy, and married girls who are in regular sexual partnerships and are often trying to have children or are under pressure to do so. The socialization of boys and girls continues to create power dynamics in sexual relationships that put young women at a disadvantage and are not beneficial to young men.

\section{Conclusion}

Further progress in the domain of power relations within sexual relationships will require both a willingness to be open to experimentation and creative approaches, and an effort to move forward simultaneously on research and program design. Research has shown that effective measurement of the gender-power dynamic lies within the realm of practical fieldbased study design. Despite initial skepticism in many quarters, programs have shown that gender-based power imbalances are not necessarily impermeable to intervention. Flexibility and adaptation to change have been demonstrated by a range of actors in programs, including individual women and men, health care providers, and the community at large. While many challenges remain, the evidence to date suggests a considerable payoff for making acknowledgment of the role of gender-based power an integral feature of reproductive and sexual health programs.

This paper can be found in full length and with full references in the September 2001 edition of Studies in Family Planning.

\section{The family planning literature} and research constructs offer a far too conventional and limited perspective on power in sexual relationships (Discussant \#1, Richard Parker) Richard Parker, of Columbia University, the State University of Rio de Janeiro, and the Brazilian Interdisciplinary AIDS Association, focused his comments on the last of the tasks addressed in Blanc's paper-calling attention to some of the gaps and problems that need to be addressed in the future. What he generally found most striking in looking at the body of research described was how remarkably conventional most of the work on power in sexual relationships within the family planning field has 
been. He laid out five areas in which this conventionality is expressed:

The very definition of power as it is used in the family planning field is too narrow The family planning literature pays limited attention to a series of developments in reflecting upon and researching power more broadly. Until we begin to incorporate into the health sciences some of the theoretical insights in relation to power developed in the social sciences, Parker said, he fears that we are destined to repeat much of the work that has already been done. It is important to emphasize that power is a social product that is socially produced, reproduced, and constructed. The most important point of this understanding is that it calls our attention to culture, a word that also does not appear in this literature in any meaningful way.

The program literature is not about sexuality as much as it is about reproductive practice

In most of the literature that Blanc reviewed, the broad-ranging issues, practices, meanings, and representations involved in sexuality are largely absent. By narrowing the focus to heterosexual relations, primarily reproductive heterosexual relations, we miss a large body of research that explores gender power, but that does not focus only on reproductive sexuality. ${ }^{2}$ Bringing this research into the discussion would be a useful step forward in thinking about the ways in which power works in sexuality more broadly.

The social context within which the family planning field's approach is framed is too limited

Parker found it striking that broader issues of social change, globalization, and the restructuring of social, political, and economic relations are not mentioned, as if sexuality exists in a vacuum with no relationship to the broader social context in which it takes place. This is particularly striking in relation to sexuality, as we have watched in recent decades the disintegration of patriarchy in countries and cultures around the world, changing family forms, and the rise of fundamentalisms. We must problematize sexuality more broadly if we are to design investigations that are not blind to these phenomena.

We must retbink our intervention strategies and research methodologies

The interventions, as Blanc's paper points out, range on a continuum from providing information to transforming community norms. Yet if we treat power as a form of structural organization, Parker asserted, then we must start thinking about structural interventions. He also called into doubt some of the faith that we place in measurement and in randomized control trials; he suggested that the

\footnotetext{
${ }^{2}$ Examples include Kennedy and Davis's study of butch-femme relations in Buffalo (Elizabeth Lapovsky Kennedy and Madeline D. Davis. 1993. Boots of Leather, Slippers of Gold: The History of a Lesbian Community. New York: Penguin Books), Annick Prieur's work on transgender sex workers and their partners in Mexico City (Annick Prieur. 1998. Mema's House, Mexico City: On Transvestites, Queens, and Machos. Chicago: University of Chicago Press), and essays in Murray and Roscoe's collection on boy wives and female husbands in sub-Saharan Africa (Stephen O. Murray and Will Roscoe [eds.]. 1998. Boy-Wives and Female Husbands: Studies of African Homosexualities. New York: St. Martin's Press).
} 
randomized control trial, which was designed as a way of testing the efficacy of different kinds of medications and medical procedures, has been somewhat uncritically adapted and applied to research on social change in ways that need to be questioned. Finally, Parker argued that the individual should not be seen as the only unit of investigation and analysis, but that dyads, couples, and communities should also be considered.

The political dimensions of relationships must be acknowledged

Sexual and reproductive rights are as important as sexual and reproductive health if we want to understand what power is and how it works in sexual relationships. What we are looking at are political issues and political changes, and that is where an understanding of power and an understanding of how to change inequality fundamentally lies.

Parker ended by saying that if we can move forward in relation to these issues, we will also move forward in terms of building a comprehensive understanding of power and how it works, and of thinking about how we might be able to shift the unequal balance of power more effectively.

\section{Power differentials between men} and women can and must be practically addressed in service programs (Discussant \#2, Jeff Spieler) Jeff Spieler, of the United States Agency for International Development
(USAID) Office of Population, offered a practical discussion of Blanc's paper. Claiming that unwanted pregnancy, STIs, and HIV/AIDS are the greatest threats to reproductive health today, and that infrequency of condom use is the primary barrier to the prevention of HIV, Spieler underlined the need to address gender-based imbalances within sexual relations. Power differentials between men and women profoundly affect the ability of women to negotiate condom use.

The stigmatization of condoms, because of an association with illicit sex, promiscuity, and a reduction in sexual spontaneity and pleasure, is a major barrier to condom use. These stigmas are especially harmful to women, who often lack the power to negotiate condom use for any act let alone for every act of intercourse. Unless condoms are disassociated from negative implications such as multiple partners, this necessary de-stigmatization will not take place. One way to achieve this disassociation, Spieler argued, is to promote condoms as effective methods for both pregnancy and disease prevention. Preliminary evidence shows that even high-risk groups such as sex workers have been more consistent and correct in their condom use if they are using them primarily for pregnancy prevention rather than for STI prevention. ${ }^{3}$

To understand the barriers to condom use, we must consider the social

\footnotetext{
${ }^{3}$ Mathias Aklilu et al. 2001. "Factors associated with HIV-I infection among sex workers of Addis Ababa, Ethiopia,” AIDS 15(1): 87-96.
} 
construction of masculinity in many of the societies with which we are dealing where the problems are greatest. Spieler highlighted Blanc's argument that male identity is often associated with power, self-reliance, and risk-taking, which contributes to men's own vulnerability to HIV/AIDS. Women, on the other hand, are expected to be ignorant of sexual matters, and thus are often inadequately informed about preventive methods. Even those women who do have access to information are not fully able to negotiate protection, whether by insisting on condom use or refusing sex. Several studies conducted in the Democratic Republic of the Congo (formerly Zaire), Uganda, and Rwanda underline this imbalance, showing that condom use is significantly higher among couples where the woman is HIV-positive, as opposed to those couples where the male is infected. This inability to negotiate is closely linked to women's inferior economic situation: women's frequent dependency on men renders them more likely to fear abandonment and the destitution that might ensue as a result of confronting or leaving their partners.

Spieler concluded by saying that condom promotion strategies must be innovative, as we face an uphill battle to get men and women to use a product that many are unwilling or unable to use. Research on the relationship between power and sexuality has been limited because power has been a difficult concept to quantify and define. Yet what is clear from recent programs is that these socially instilled gender imbalances are not impermeable to change, and programs have to develop creative strategies to reach men.

Power in sexual relationships is inextricably linked to the balance of power between men and women and wider considerations of equity in development (Discussant \#3, Geeta Rao Gupta)

Geeta Rao Gupta, of the International Center for Research on Women, began her presentation by commenting that the interest in the balance of power between women and men occurs within a context of a renewed interest in equity and equality as goals of development (see box). This recent rise in the social approach to development has occurred because of increased recognition of the tremendous economic, social, and political costs associated with persistent inequalities that are unfair and avoidable.

Applying what has been learned from much of the research that Blanc reviewed as well as her own programmatic experience, Gupta discussed several critical dimensions of power:

Types of power: "Real" vs. "perceived" Gupta defined "real power" as the actual attributes that coincide with how society views and defines power (e.g., education, money, leadership). "Perceived power" is derived power due to a strong association in the aggregate between a single characteristic (such as being a man) and the 
attributes associated with power. She stressed the importance of changing perceived power; however, she claimed, the only effective and sustainable way to change perceptions is to create changes in real power, because over time those changes in the aggregate will begin to constitute a critical mass that will alter perceptions. We must therefore argue for changes in policies and programs that seek to increase women's access to key resources and positions of leadership rather than just trying to alter perceptions of male and female roles.

Context of power: Individual vs. aggregate Gupta argued that increasing individual women's access to economic resources and social status in a context where such access is not the (aggregate) norm will not necessarily afford them greater power in sexual relations. For women to accrue such power, individual interventions must be complemented with efforts to alter the aggregate picture of women's socioeconomic status.

Content of power: Economic, buman, and social capital vs. agency to act

Gupta asserted that empowering individuals requires strengthening access to resources and building individual agency to use those resources, make decisions, and take leadership. The former, she said, is concrete, the latter is "magical" (because one can create the enabling conditions for the latter, but cannot guarantee the outcome). Enabling empowerment within development interventions involves creating opportu-
"INEQUALITY" IN HEALTH is the difference between groups based on objective indicators.

"Inequity" in health is a subset of inequalities deemed unfair because they are avoidable and unjust. At the World Conference on Women in Beijing in 1995, participants debated which term to use. The UN, with support from the NGOs, chose to use the concept of "equality" because definitions of fairness, inherent in the definition of equity, were subjective and differed greatly between participants of different ideological backgrounds, whereas equality could be more objectively defined.

nities for learning problem-solving and decisionmaking skills, altering practices and perceptions of local institutions and leaders, and building partnerships within communities and between individuals and local institutions. A sense of agency or empowerment, while objectively associated with many positive health and development outcomes, is itself largely subjective, a personal perception of how one feels in relation to others and one's environment. Measuring empowerment, therefore, requires subjective indicators that can capture this perception or experience.

\section{Discussion}

The first set of discussions was characterized by a tension, present throughout the meeting, between the broadest discussion of what is necessary to change the 
GUPTA READ THE WORDS of a young abandoned married woman in India who participated in a village program as a community welfare worker, as one example of a definition of empowerment:

I was told by my mother and grandmother not to talk to anybody. I did not know anything beyond this village when I first came bere. I could not go to visit anybody, was not allowed to go to weddings, but something magical bappened being part of this project. Now I can go outside the village to the post office, local government, and district government offices on my own to get things done. Before, nobody taught me anything, just put restrictions on me. I was living for the sake of living. Now I want to live like a buman being. Now I won't like living like that, and I won't let anyone else live like that. People would say, "What is she going to do?" Now the same people come to me for help. I was not much educated. Now I bave insisted that my sister get educated, and the girls in the village, too. Now the girls bave an opportunity to learn, to play. They say, "Let's forget the past. We are not like anybody else." I will never forget what the people in this program bave taught me.

societal forces that create power imbalances and the more narrow practical and tactical approach of seeking to reform traditional interventions (incrementally improving upon existing reproductive health service models). In this discussion, as in others, many speakers acknowledged the need for both, but there were clear biases as evident in the quotes below.

For the broader inquiry:

If we are going to move forward we must move all the way forward — not stay within traditional indicators, modes of evaluation.

Work over the past twenty years bas found that using quantitative instruments is not enough. ... What's missing is a more bolistic understanding of the complexity of relationships, of love and power.

We are dealing with individuals but leaving structures untouched. One of the biggest structures is compulsory beterosexuality. How is this dealt with when we talk about gender roles?

Are rights-based approaches really meant to be evaluated the same way as regular public bealth interventions?

For more immediate practical approaches:

Most of us come from a public bealtb background, so bearing about these structural changes can feel a little overwbelming. There are a number of things we can do within our work to carry this out-for example, integrating sexual violence into the work of already existing programs. We need to think about what we already do and bow we can be more sensitive.

I am in the camp of those interested in the effect of $A$ on $B$ after controlling for $C$. I feel optimistic about the possibility of quantitatively measuring and assessing impact on sexual and reproductive bealth outcomes. If we look at what has been done before, there is a lot that is pretty good, including multi-level measurement.

It is sufficiently ambignous that things like male involvement make an appropriate difference in public bealth terms that it is appropriate that we stick with randomized control trials despite what was said this morning. A concrete example of what can bappen when we proceed without attention to underlying gender analysis and research can 
be seen in the case of condom promotion.

Recent research in Brazil-informed by masculinity studies — has found that men's and boys' complaints about reduced sexual pleasure with condoms to a large degree provide socially acceptable "cover" for a deeper preoccupation with sexual performance (i.e., the reasonable fear of losing one's erection while putting it on). Yet we have spent tens of millions of dollars on condom promotion campaigns which bave completely overlooked this phenomenon. 


\section{FIELD-BASED EFFORTS: SERVICE DELIVERY}

The exploration of field-based efforts began with the presentation of two programs designed to effect change at the level of service delivery. The first described the necessity of addressing providers' own dynamics of social power and power in sexual relationships as a precondition to enabling them to assist clients with their own dilemmas. The second demonstrated that a demand exists, as does a precedent, for involving men in certain aspects of reproductive health, but that providers and service-delivery systems must adapt their attitudes and practices to accommodate this demand.

\section{WHEN DESIGNING the provi-} der training program, the research team came to understand the difficulty of translating the idea of "power." For the purpose of the intervention, they deemed the main components of "empowerment" to be:

- Knowledge

- Self-confidence

- Negotiating skills

- Awareness

- Communication skills
Empowering clients equals empowering providers:

An example from Pakistan (Anrudh Jain and Zeba Sathar) ${ }^{4}$ Anrudh Jain and Zeba Sathar, of the Population Council, described a project in Pakistan entitled "Introducing a Client-Centered Approach to Reproductive Health Services." The main objectives of the intervention were to bring about a change in providers' attitudes and behaviors, and to empower clients to become actively involved in their own reproductive health. The intervention, which took place in a poor, rural district in Punjab, heeded previous research that linked poor reproductive health outcomes to the restricted mobility of Pakistani women, their limited resources, and their lack of power in the household.

The intervention involved training 95 community health providers working with the Ministry of Health or the Ministry of Population and Welfare. These women were native to the communities that they served, and therefore were inhibited by the same set of constraints as the clients they served, including limited mobility and control of their earnings-factors deemed critical to address in the training.

\footnotetext{
${ }^{4}$ For more information on this project, contact Zeba Sathar at zsathar@pcpak.org.
} 
The objectives of the provider training were:

- To raise awareness about power and equality in the providers' own daily lives, in the lives of their clients, and in their interactions with their clients; and

- To teach them communication skills that responded to these power dynamics.

Exercises included mapping sources of power, discussing alternative ways to "open a tight fist" besides physical power, and defining types and grades of power. The communication skills training emphasized the need to be respectful, to assess clients' reproductive health needs beyond the immediate problem (i.e., through asking openended questions), and to address clients' domestic realities. Specifically, providers learned to observe who in the household held the power (such as the husband and the mother-in-law); to be sure to acknowledge his or her reproductive health intentions as well as those of the client when negotiating an appropriate solution; and to ascertain that, at the end of a visit, the client understood and would be able to implement the course of action agreed upon.

From focus group interviews, feedback from the trainers, process studies, and visits by the presenters (the situation analysis study results are not yet available), it is apparent that the training has had significant influence

\section{CHANGES IN ATTITUDE AND BEHAVIOR}

become apparent when listening to the women's words:

Previously we talked in front of everybody, now we judge

who bas the power of decisionmaking in the bousehold and then

first talk with them ... then with the client ... those women

who cannot talk to their busbands, we try to belp them

through a feeling of self-awareness and through showing them

"power to."

My clients thought I was young, I felt shy, I could not talk

openly, but now (after the training) I speak with confidence and

they open up and tell me everything.

on both the providers' private and professional lives. They report feeling more confident about moving about outside of their homes, becoming more assertive in their own marital relationships, and taking action against domestic violence and harassment at work. They also report more patience with their own children. Changes in their professional behavior include making deliberate efforts to be "equal" with their clients (e.g., sitting at the same level when they are in their homes, avoiding one-way lecturing, and spending more time with their clients). They now consider and address other sources of power, for example, by dealing with the husband's influence through the motherin-law. Finally, they generally feel more motivated and excited about their work. 
Integrating male partners into the reproductive health equation:

An example from Kenya

(Esther Muia) $^{5}$

Esther Muia, of the Population

Council's Nairobi office, discussed a study examining the acceptability and feasibility of integrating male partners into reproductive health services in Kenya. Despite men's influence on women's ability to access services and implement regimes of care, research documented that male partners were actually marginalized within the mainstream of reproductive health care services. Muia and her colleagues sought to understand the actual and potential role of men as supportive partners by identifying current participation; assessing the attitudes of women, their partners, and service providers toward the participation of men; and identifying barriers to male partners' greater participation.

They carried out their study in 1998 in a provincial hospital in a largely rural area of Kenya's Western Province and in a teaching hospital in urban Nairobi. Qualitative and quantitative techniques were used to collect information from women receiving reproductive (in- and outpatient) health services, men accompanying their partners, partners of women who did not accompany their partners (who were followed up at work, at home, or elsewhere in the community), and service providers. One- third of women at the urban site were accompanied by their partners, compared to one-sixth at the rural site.

A vast majority of the female and male respondents indicated that men's participation was desired in antenatal, postpartum, and family planning visits. An overwhelming proportion (94\%) of the women said that they would like their partners present during their consultations, to assure their understanding and support of the doctor's advice. An even greater proportion (98\%) of men said they would like to be present. Despite the lack of cultural precedent as well as strong provider opposition (see below), 50\% of women and 46\% of men said that it would be appropriate to have the man present in the delivery room. The views of service providers were for the most part similar to those of their clients: they believed that partners should be present during counseling and when discussing the client's condition; a much smaller proportion $(1 \%-5 \%)$ wanted partners to be present when examining the patient or in the delivery room.

Muia identified the key constraints hindering male participation to be:

- Financial (transport costs for two people, time off from work, partners working away from home);

- Social/cultural and peer pressure (certain activities are not considered "manly");

\footnotetext{
${ }^{5}$ For a more in-depth discussion of this study, refer to Esther Muia et al. 2000. "Integrating men into the reproductive health equation: Acceptability and feasibility in Kenya," New York: Population Council, or contact Esther Muia at emuia@popcouncil.or.ke.
} 


\section{Where respondents would like to see greater participation of male partners in reproductive health services}

\begin{tabular}{lrrr} 
Service type & $\begin{array}{r}\text { Female respondents } \\
(\mathrm{N}=697)\end{array}$ & $\begin{array}{r}\text { Male respondents } \\
(\mathrm{N}=284)\end{array}$ & $\begin{array}{r}\text { Service provider } \\
\text { respondents (N=196) }\end{array}$ \\
\hline Antenatal care & $632(91 \%)$ & $253(89 \%)$ & $118(60 \%)$ \\
Consultation & $655(94 \%)$ & $279(98 \%)$ & $98(50 \%)$ \\
Examination & $468(67 \%)$ & $183(64 \%)$ & $2(1 \%)$ \\
In the labor ward & $438(63 \%)$ & $176(62 \%)$ & $10(5 \%)$ \\
During delivery & $351(50 \%)$ & $132(46 \%)$ & $10(5 \%)$ \\
Postpartum visits & $644(92 \%)$ & $257(90 \%)$ & $88(45 \%)$ \\
FP clinic & $622(89 \%)$ & $246(87 \%)$ & $98(50 \%)$ \\
Pay for services & $669(96 \%)$ & $182(64 \%)$ & $176(90 \%)$
\end{tabular}

- Institutional (overcrowding, lack of privacy, provider attitudes); and

- Poor communication (between the couple, and between clients and providers).

There are many important points to be drawn from this study: that men, women, and providers do see a space for greater partner participation in services; that men are presently participating despite barriers; that some reproductive health services are seen as more appropriate and acceptable than others for male participation; and that women, men, and service providers do not always agree on when male partners should be included. Taking these lessons into account, an intervention has been proposed for Western Kenya that will work with female clients, their partners, and providers at various levels of service provision to ascertain appropriate and acceptable ways to increase men's involvement in selected reproductive health services. This could include creating a space for accompanying partners; including male partners in selective aspects of service delivery such as counseling and consultations; determining appropriate ways and means of sharing information on women's reproductive health needs and problems with male partners; and developing verbal protocols for opening discussion of power in sexual relationships.

\section{Discussion}

Discussion centered around the idea of male presence in reproductive health services. One participant noted that men are often excluded from the health care of young children as well. He cited a survey in Zambia in which men suggested having fathers' days for under-5 checkups. The men hoped to take their chil- 
dren to the clinics to gain access to some

of the information that was usually disseminated to mothers within the maternal and child health programs.

Other participants revisited an ethical question raised by Blanc: Is there a risk that more involvement and infor- mation will perpetuate male control over female decisions? Within the counseling context, for example, there is the danger that providers may begin talking to the man instead of addressing the woman or both members of the couple. 


\section{FIELD-BASED EFFORTS: C O M MUN I T Y}

The second group of field practitioners described larger-scale interventions at the community level. The first presenter depicted a multi-level intervention designed to increase dialogue at the community level and work directly on social norms governing power in relationships. The second described a practical community-based and clinicbased effort addressing men's and couples' roles, communication strategies, and power dynamics. And the third explained how out of a women's reproductive health problem emerged women's wishes to work with their partners, and the practical steps taken to engage men in the community.

Linking health, development, and empowerment: An example from India (Hemant Apte) ${ }^{6}$

Hemant Apte, of KEM Hospital Research Centre, spoke about linking health, development, and empowerment in interventions undertaken in rural Maharashta State, India. KEM's community-based activities currently reach 150 villages with a total population of 200,000.

In a 1995 survey of 500 boys and girls aged 14-22 (both married and never married), KEM found that adolescents had very little scientific knowl-
IN INDIA, THERE IS A SAYING that "an intellectual's identity is not complete without an institution, a creeper's without a tree, or a woman's without a man." We want women to recognize their independent humanity.

-Hemant Apte edge about sexual and reproductive health, and that girls had less knowledge than boys. Sexual and reproductive health issues were found to be the concerns not only of the couple, but of the entire kinship circle. The study confirmed that the power balance was heavily tilted against adolescents, and particularly against females. For example, most married adolescent females said they were unable to decline sex; almost all first births took place within the first year of marriage because giving birth was seen as the only way for a girl to establish herself in her husband's household. However, the study also found that when men had a degree of economic independence from their families, some education, and had established separate families themselves, there was better communication between spouses and a greater role for the women in reproductive health decisionmaking.

KEM has fielded a range of interventions, both before and in response

${ }^{6}$ For more information on this work, contact Hemant Apte at ham@pn2.vsnl.net.in. 
to the study, to address both issues of women's empowerment and male involvement in reproductive health. Among these interventions are groups promoting collective action by girls (separate groups for married and unmarried), women's income-generation schemes, couple education programs, and men's reproductive health education activities.

Apte described in detail three major interventions:

Addressing adolescent males and their role in reproductive bealth

Adult males (supervisors of female community welfare workers) held educational groups with approximately 20 married and unmarried males between the ages of 16 and 25. These two-hour sessions covered subjects such as male and female reproductive anatomy and physiology, male and female stereotypes, the role of husbands and partnerships, and STIs and HIV/AIDS. Apte noted that this was the first time these boys had been involved in a discussion about either male or female anatomy. Through roleplaying, the boys began to recognize the tremendous inequality pervading their relationships with their girlfriends and wives (e.g., saying "Get me some water, I have to wash my face" or "Is the tea ready?"). Apte said that the young men had not been conscious that they were exercising so much power and control, and of the consequences to their partners. Sixteen of these young men have now volunteered to give this same training to others in their communities.
Couple education program

This day-long program, held for groups of 10-12 (mainly younger) couples, covers women's and men's reproductive health, the pervasiveness of gender inequality, and how men unconsciously use power. The main purpose is to foster dialogue on these subjects. To this end, one of the activities used was a role play with the men wherein one took on the role of a wife and another the role of a husband. The "couple" was asked to act out routine household interactions in front of the whole group. Afterward, the man who played the wife was asked how he felt listening to what his "husband" was saying. Throughout the different sessions, the men acting as wives admitted feeling hurt and finding the other men's actions and remarks derogatory.

\section{Village-based clinical services}

for women

A female doctor from the KEM Hospital Research Centre provides clinical services once a week in a 30-bed rural hospital in Vadu. The doctor speaks with the women about their problems and also about the role of their husbands; in some cases (i.e., when they are found to have an STI) women are asked to bring their husbands with them on the next visit. Some husbands have now begun to come in with their wives. In addition to the reproductive health services, counseling services on sexual issues will be offered by a clinical psychologist on a bi-weekly basis where clients, male 
and female, will be able to come in alone or as couples for consultation.

KEM realized that although it covered 150 villages—no small feat-it still did not come close to meeting the needs of the entire state. It is therefore now providing training of trainers to district-level health personnel from other parts of Maharashta State on various aspects of reproductive health including male involvement because all of these aspects are now being included within the government program.

\section{Fostering a community dialogue} on sexuality and reproductive health: An example from Belize (Jewel Quallo-Rosberg) ${ }^{7}$ Jewel Quallo-Rosberg, of the Belize Family Life Association (BFLA), a Caribbean affiliate of the International Planned Parenthood Federation, described the Association's shift from a clinic-centered program and one-directional didactic monologues about contraception to a frank, two-way dialogue on sexuality and reproductive health conducted in both clinical and community settings. She described a process in which the community readily and urgently identified the power imbalances that left women vulnerable as victims of unwanted sex, domestic vio- lence, infidelity, unwanted pregnancies, and sexually transmitted infections.

Developing an appropriate strategy to deal with the intense power struggle between men and women in the intimate sphere required a good deal of thought to foster a process that would be safe and effective for all parties. Men in the community felt misunderstood and disempowered by society (many of them were unemployed or low-income earners) as well as by their partners, and women felt that they were carrying a disproportionate responsibility for families and that men wanted to control everything and tell them what to do. Women were often forced to use contraceptive methods covertly (such as putting oral contraceptive pills in vitamin bottles or using injectables) because they faced verbal and physical abuse if discovered.

Among the strategies BFLA has tried are:

- Altering clinic protocols and training counselors so that providers are encouraged to ask questions about communication and power in intimate relationships and to reinforce clients'-usually women's-reproductive and sexual rights;

- At the community level, training volunteers to be facilitators of regular group dialogues where gender and power are discussed openly; ${ }^{8}$

\footnotetext{
${ }^{7}$ For more information on BFLA's work, contact Jewel Quallo-Rosberg at bfla@btl.net.

${ }^{8}$ For more description of these group dialogues, see Lucella Campbell and Mervin Lambey. Forthcoming. "How a family planning association turned its approach to sexual health on its head: Collaborating with communities in Belize," in Nicole Haberland and Diana Measham (eds.), Responding to Cairo: Case Studies of Changed Practice in Reproductive Health and Family Planning (working title). New York: Population Council.
} 


\section{Communication between partners:}

Fishbowl exercise (30-45 minutes with mixed gender groups)

PURPOSE: To practice using good partner communication and analyze the problems that arise between sexual partners.

\section{Getting Ready: Prepare four or more situations}

for people to role play. In each situation, there should be an issue or problem to discuss. Here are some examples:

- Woman whose partner is threatening to leave her. She wants him to use a condom when they have sex.

- Woman whose partner has had children with other women. She depends on him for money for her family.

- Girl with an older boyfriend. He wants her to have sex and she is not sure she wants to. She really loves him.

- Man who wants his partner to use family planning. She is not sure she wants to.

WHAT TO DO: Ask for volunteers to play the man and the woman and to practice communicating with each other as they act out these scenarios. The rest of the group watches and helps to analyze what works and what could be done better. It may be helpful to make lists reflecting the group's definition of what constitutes good communication (e.g., two-way communication, listening, empathy) and what constitutes bad communication. If possible, everyone should have a turn at role playing and observing.

FACILITATION TIP: Before commenting, give those who did the role play the first opportunity to say what they think went well, and what they wish they had done better. Then the observers' comments will feel more helpful and less like criticism.
- A parenting education program that equips parents with skills needed to communicate more effectively with their children and free them from confining and destructive gender roles;

- Establishing peer-to-peer sessions for adolescents-both girls-to-girls, and boys-to-boys-that cover issues of sexuality; BFLA also conducted home sessions where parents listened as adolescents discussed issues of self-esteem, sexuality, and their feelings; and

- Presenting street dramas written by community members to generate discussion.

Engaging men as a separate and special constituency was an integral part of BFLA's strategy to increase communication between the sexes and reduce tensions. Such sessions were necessary to deal with the feeling, as Quallo-Rosberg put it, that "men were experiencing pain and anxiety, but were unable to voice it." Male-only groups were particularly valuable in eliciting concerns about unemployment and male powerlessness, feelings of disrespect from women, issues of control and dominance, and erectile dysfunction. They also conducted mixed male/female discussion groups using a moderator to permit men and women to hear each other's concerns (see box for example of an exercise used). Finally, they created an environment that encouraged women to bring their partners and that made them feel comfortable once there. 
BFLA is currently refining its service protocols so that all client-provider exchanges include discussion of the balance of power in sexual relationships. The goal of the new protocol is to encourage presenting clients to talk about partner dominance and abuse, explore ways to negotiate with insecure partners, and assist in equalizing relationships. The agency will also urge clinic staff to get out into the community and assist in the creation of women's support groups throughout Belize-to learn whether the experiment conducted to date in Belize City (where most of the residents are of Creole origin) will be equally accepted in the north, west, and south of the country (where a large proportion of residents are Mestizo and Garifuna).

Incorporating men, as articulated by women: An example from Peru (Susana Galdos) 9

Susana Galdos, of the Movimiento Manuela Ramos's ReproSalud project, discussed how this historic project made changing the balance of power in sexual relationships a central element in its work. A large USAID-supported project, ReproSalud goes into communities where government and family planning programs have largely failed to find an audience. It invests in the social and economic development of women so they will be better able to exert control over their own lives. Although reproductive health education and gender awareness are the center of ReproSalud's work, no less than $16 \%$ of the project budget was allocated to income-generating schemes and credit programs. Galdos explained how a project designed only for women came to work with men as well.

One of the most innovative aspects of ReproSalud is the process it has used to assess the needs of the communities it serves. ReproSalud staff go into the communities and ask women what they want and need through an open-ended self-assessment process known as autodiagnóstico (self-diagnosis). Common reproductive health problems identified by the women include reproductive tract infections, too many children, problems during pregnancy or childbirth, and violence. Group exercises also enable the women to analyze the social roots of their health problems. The women are then invited to organize a community project to address a key problem, in which ReproSalud trains local women to educate other women in the community and gives the group technical and economic support.

As Galdos explained, as the women became deeply engaged in and excited about addressing their problems at the root level, they were emphatic that,

\footnotetext{
${ }^{9}$ For a more in-depth discussion of the Manuela Ramos Movement and ReproSalud, see Debbie Rogow and Judith Bruce. 2000. "Alone you are nobody, together we float: The Manuela Ramos Movement," Quality/Calidad/Qualité, no. 10. New York: Population Council.
} 
GALDOS PRESENTED sample testimonies from the men who participated in the workshops as well as from their wives:

They bave taught us about family planning, about diseases, bow to care for our sexual organs. And we've learned bow to live together in the family. That we have to work equally and that we bave to take care of our wives. For example, to live without fighting, to take women to the bealth centers if they are sick. ... My favorite part of the course was about living together, taking care of the children and our wives.

—Lorenzo, promoter

Before, I drank a lot and bit my wife. Then I felt bad and wondered why I did it. Now I drink less and I do not bit ber. I talk to my oldest daughter (nine years old) and encourage ber to study.

—Victorio, age 30, promoter, Canchabamba

I can talk to bim more openly now. For example, I used to be embarrassed if be touched me a lot. I can tell bim now where it feels good, in the vagina, the clitoris. He asks me and I can tell bim.

—Victoria, age 32, 5 children, Acopalca

Before, when our busbands bit us, we sat quietly and cried. Now we are not afraid. We can file a complaint; some women are doing that. Before, no. We were just cooking and crying. My busband was very difficult before. Now be went to the men's training. And be is more affectionate.

—Rosa Maria, age 35, 7 children, Huarimayo shifting resources away from women's activities, but modified the project's design in response to the demands of the women.

A group of men who knew the local cultures and languages were selected to attend a national training-of-trainers workshop. These men then trained male promoters from the villages, who, following the ReproSalud model, offered the workshop to other men in their communities. Consisting of 12 hours of material presented over four sessions, the workshops used exercises and intense discussion to explore the involvement of men in violence, alcoholism, sexuality, and fatherhood, and to discuss reproductive and sexual anatomy and physiology, women's rights, gender roles, contraception, the particular reproductive health issues prioritized by the women in their community during the self-diagnostic workshops, and the role of men in domestic abuse.

Pre- and post-tests demonstrated significant changes in the participants' knowledge and attitudes. Men valued the opportunity to learn about their bodies and about sexuality, and were also eager to explore ways to promote harmony in the family. Other benefits included increased understanding about self-care and hygiene, their wives' rights (e.g., to refuse sex), and their role in child care. Disadvantages cited by men of participating in the ReproSalud program included being criticized by other men as being "hen-pecked," feeling threatened by women's increased agency, and 
their wives' being less tolerant of them.

As part of a 1999 multi-site evaluation, Debbie Rogow and Alejandro Diaz conducted a case study assessment of ReproSalud in several Andean villages. ${ }^{10}$ They found that the changes documented after the training had been sustained over time. Some of the most impressive changes reported included increases in female and male selfesteem; drastic reductions in male alco- hol consumption and related domestic violence; and marked increases in contraceptive use. Many respondents reported greater decisionmaking by women and more sharing of responsibilities on family matters.

Ultimately, training men to work as educators of men in their own communities has become one of the most salient facets of ReproSalud's work with women in Peru.

${ }^{10}$ Debbie Rogow and Alejandro Diaz. 1999. "ReproSalud: Evaluation of project impact in the Chavin region: A case study," unpublished trip report to USAID/Lima and ReproSalud. 


\section{FIELD-BASED EFFORTS: S O C I A L I Z AT I O N}

Studying socialization is crucial to understanding how gender roles are created. There is good reason to believe that styles of interaction in intimate relationships are learned in childhood and "rehearsed" during adolescence. Presenters shared the approaches, experiences, and findings of several projects in Latin America attempting to address and understand male gender socialization. The first example provides a realistic portrait of change-whereas gender roles and sexual norms are undergoing secular change, some traditional and not necessarily positive norms are slow in disappearing. The second program described emphasizes the heterogeneity of the male youth population, exploring the situation of "genderequitable" young men. The third program explores how the traditional construction of "masculinity" brings risks to both genders.

Night was made for men:

Courtship and sexuality in a rural town in Mexico

(Benno de Keijzer) ${ }^{11}$

Benno de Keijzer, of Salud y Género, first reported on ethnographic research he and his colleague Gabriela Rodríguez conducted in Iguanillas, Puebla. The study, carried out among three generations of men and women over a twoyear period, examined how courtship and sexuality are changing.

The investigators found a cultural transformation taking place among the young in Iguanillas. Overall, they found a tendency among younger people toward more equity in gender, and some evidence of an emerging openness toward female sexual initiative and right to sexual pleasure. The key factors they cited in the cultural transition included:

- Migration (about one-fifth of the local population currently live in the United States);

- The relatively new local school, which contributed to creating a new "youth" culture and expanded adolescence;

- Images of love and sexuality in popular media; and

- The waning influence of religion.

As Rodríguez and de Keijzer wrote in a separate article on the study, "Our adolescent informants seduce, love, and hurt women; but the women, no longer as passive, are reacting to and taking ideas from the youth of other cities, from the school, from the media, and from the migrants." 12

\footnotetext{
${ }^{11}$ For more information on this study, refer to Edamex and the Population Council, Mexico. Forthcoming. "La noche se hizo para los hombres: cortejo y sexualidad en una comunidad cañera del estado de Puebla."
} 
However, many traditional norms are still upheld even among the younger generation. Female virginity is still valued, and its "loss" is a precipitating factor in the formation of couples. Males are still expected to demonstrate sexual performance at an early age, with virtually all young men going through "sexual initiation" in the brothels once they begin earning money. This initiation occurs "with clean horns," or without condoms, something they brag about. Informants also tended to deny that premarital sex, abortion, and homosexuality were present in the community, although in fact they all are. According to de Keijzer, adult men typically have a double standard for male vs. female sexuality, holding women and girls accountable for limiting their sexual behavior. For example, fathers of adolescent and even younger sons use the phrase, "Watch your chickens, my rooster is loose." Further, the investigators found that the gains observed in equity among youth tended to erode after marriage and first childbirth.

\section{Involving young men and} adolescent boys in Brazil (Gary Barker) ${ }^{13}$

De Keijzer then spoke about the research Gary Barker of Instituto
“Gender EQUitable" refers to young men who:

- Are generally respectful in their relationships with young women and currently seek relationships based on equality and intimacy rather than sexual conquest, and believe that men and women have equal rights, and that women have as much sexual desire and "right" to sexual agency as do men.

- Seek to be involved fathers, meaning that they believe that they should take financial and at least some care-giving responsibility for their children. They have shown this involvement by providing at least some child care, showing concern for providing financially for the child, and/or taking an active role in caring for their child's health.

- Assume some responsibility for reproductive health issues. This includes taking the initiative to discuss reproductive health concerns with their partner, using condoms or assisting their partner in acquiring or using a contraceptive method.

- Do not use violence against women in their intimate relationships, and are opposed to violence against women. This may include young men who report having been violent toward a female partner in the past, but who currently believe that violence against women is not acceptable behavior, and who do not condone this behavior by other men.

${ }^{12}$ Gabriela Rodriguez and Benno de Keijzer. 1997. "Sexualidad juvenil: relato etnográfico de una comunidad rural," presented at the conference Aproximaciones a la Diversidad Juvenil, El Colegio de México, 5-6 November.

${ }^{13}$ For a more in-depth discussion of these concepts, refer to Gary Barker. 2000. "Gender equitable boys in a gender inequitable world: Reflections from qualitative research and program development with young men in Rio de Janeiro, Brazil," Sexual and Relationship Therapy 15(3): 263-282. Barker can also be contacted directly at g.barker@promundo.org.br. 
WHAT MAKES SOME BOYS more gender equitable?

- They have reflected upon the costs of traditional views of manhood.

- They have constructed a coherent life narrative of themselves as different from most men around them.

- They have been victims of violence, have witnessed people being victimized, or even enacted violence themselves, and have been able to reflect about the costs of their violence, and to express pain or remorse.

- They have become fathers and used that experience to reflect about their roles and responsibilities in positive ways.

- They have positive male role models who show respect in their relationships with women and encourage them to do the same.

- They belong to a group of male peers (vocational or cultural) who support male involvement in reproductive health and encourage them to do the same.

Promundo has conducted among adolescent boys in the United States and Brazil. Barker studied a group of 25 young men aged $15-21$ in a low-income setting in Rio de Janeiro, where masculinity is largely associated with limited involvement in reproductive health and child care, a sense of entitlement to sex from women, and a fairly widespread tolerance of violence against women. Barker attempted to understand why even in settings such as this some boys act in more gender-equitable ways. The study identified an important minority of young men who demonstrated a higher degree of gender-equitable behavior and attitudes in their interactions with young women than did most of their peers and adult men in the same setting. The results (see box) suggest that some boys are able to reflect and grow from critical experiences, such as seeing the conse- quences of a man being violent toward a woman or abandoning his children. In addition, these boys are more likely to have adult men or peers in their lives who model respect in their relationships with females and who support male involvement in reproductive health.

One of the most important lessons learned from the work by Promundo is that male youth are a heterogeneous population with a wide range of behaviors and priorities that change over time. When boys interact with adults and peers who are involved in caring for children or domestic tasks, with women involved in leadership positions, or with men who show responsibility for reproductive health, they are more likely to be flexible in their ideas about men's and women's roles and to become involved in reproductive health. Program implications include supporting gen- 


\section{Masculinity as a risk factor}

FOR WOMEN

Violence

STIs/HIV

Unwanted pregnancy

Depression

Limited opportunities
FOR MEN

Incarceration

Drug/alcohol abuse

Suicide

Violence/homicide

Shorter life expectancy der-equitable young men and finding ways for them to serve as role models for other young men, creating alternative peer groups that espouse genderequitable attitudes and behavior, and raising community awareness about domestic violence and gender equity. It is also important to reach boys early, as early as ten years of age, when they are more likely to be receptive to alternative views of male gender roles. Youth programs need to encourage boys to reflect on their own experiences and to question traditional gender norms, including examining the benefits of greater gender equality for themselves as well as women. Boys should also be taught new communication and negotiation skills, as research and field experience suggest that the key to reducing HIV transmission and achieving greater male involvement in reproductive health lies in improving communication between partners. Finally, given that many boys believe that sexual intercourse is the only "sex that counts," programs should work with boys to explore other ways of expressing affection, including sexual expression.

\section{Addressing masculinities in} Mexico (Benno de Keijzer) ${ }^{14}$

Finally, de Keijzer talked about his own work with Salud y Género addressing "masculinities." Salud y Género is a civil organization in Mexico devoted to studying and changing some of the main consequences of gender relations for the reproductive, sexual, and mental health of women and men.

De Keijzer and his colleagues have conducted workshops since 1990 with a highly diverse population of men and boys. In these workshops men explore how traditional masculinities pressure men to appear strong, competitive, and invulnerable, to avoid intimacy (with women and other men), and to subscribe to misogyny and homophobia. They also help males understand how hegemonic masculinity turns into a risk factor for both women and men (see box), contributing to men's shorter life

\footnotetext{
${ }^{14}$ For a more in-depth discussion of these issues, refer to Benno de Keijzer. 1999. "Reaching men for health and development," in Linda King (ed.), Questions of Intimacy: Retbinking Population Education. Hamburg: UNESCO.
} 
expectancy — on average a deficit of as much as six or more years in Mexico compared to women.

Salud y Género is now boosting its capacity to evaluate and document the impact it is having with men and women. Specifically, it is trying to determine how to study changes not only in attitude but also in behavior among the men who attend its masculinity workshops, as well as how these changes are affecting family, work, and community relationships. In the future, Salud y Género will place priority in its interventions on fatherhood, partnership in the process of childbirth, stopping violence against women, and helping young men address HIV/AIDS.

\section{Discussion}

In the discussion, several participants brought up the need to talk about men's empowerment, and to debunk the myth that all men are powerful.
Negotiation, communication, self-confidence, and awareness are skills that young boys lack in their socialization and that adult men could use as well. As was seen in these case studies, lack of men's sense of empowerment can translate into negative behaviors that seriously affect women. Without looking at how to change masculinities, there will be no lasting change for all. Toward this end, participants discussed the need not to teach men a certain role, but rather to give them space for reflection.

Participants also reemphasized the potential of fatherhood (particularly among first-time fathers) as a useful moment for intervention. De Keijzer said that one of the most striking experiences Salud y Género has had has been getting young men to reflect on their own fathers, and using that as the basis to start planning what they will want to be like as fathers and men. 


\section{COMMENTS FROM THE COMMUNITY OF DONORS AND IMPLEMENTING AGENCIES}

All of the efforts described above have been nurtured by institutions that have been creative and forward-thinking with their support of programs that try to address this difficult theme. Representatives of some of those key institutions spoke of their organizations' experiences in fostering experimentation and change, as well as their visions of future work and priorities.

\section{USAID Interagency Gender}

Working Group's (IGWG) Men and Reproductive Health

\section{Subcommittee}

Below is a statement offered by

Sam Clark:

In 1997, the Office of Population convened the IGWG, with broad participation from cooperating agencies (CAs), donors, and other individuals and agencies working in the field of reproductive health. The Men and Reproductive Health Subcommittee, one of four working committees within the IGWG, holds meetings quarter$1 y$, which are attended by $25-35$ individuals representing some 30 organizations. The core values of the Subcommittee are: to promote women's empowerment and gender equity, particularly in reproductive health; to increase men's support for women's sexual and repro- ductive health and children's well-being; and to promote better reproductive and sexual health for men and women. We have chosen three priority areas for our work: male adolescents, dual protection from a gender perspective, and genderbased violence.

There is a healthy tension within the Men and Reproductive Health Subcommittee between those who want to focus on reproductive health programs that involve men to serve the needs of women, children, or men; versus those whose primary concern is to address gender inequality through reproductive health programs. Let me give you an example. One might have a condom promotion program for men that succeeds in increasing condom use, with beneficial health outcomes for men, women, and children, but is entirely neutral as far as gender equity is concerned. In contrast, one could promote condoms in a way that stresses the equality of men and women and in so doing increase condom use and gender equity at the same time. The Subcommittee stresses the latter approach, using gender-equitable strategies to improve reproductive health outcomes, and this should be our main "value added."

The Subcommittee's activities have focused on providing a forum for ideas and information exchange, improving 
There is a bealthy tension within the Men and

Reproductive Health Subcommittee between those who

want to focus on reproductive bealth programs that

involve men to serve the needs of women, children, or

men; versus those whose primary concern is to

address gender inequality through reproductive bealth

programs. The Subcommittee stresses the latter

approach, using gender-equitable strategies to improve

reproductive bealth outcomes, and this should be our

main "value added."
It must be understood that men benefit from their participation as well as women, and that they are not purposely avoiding involvement in order to harm their partners; simply, men have traditionally had no place in the reproductive health service environment and a way must be found to institutionalize their participation.

The issue of sexuality as it relates to power must be broached explicitly, both within the Subcommittee and elsewhere, and not just implicitly as it has been in the past. An example of a sexuality issue for men is cultural taboos against masturbation, such as on the Indian sub-continent. In such cultures, young men may feel they literally have no acceptable outlet for sexual expression other than intercourse, even if it means risking HIV/AIDS with a commercial sex worker. Alternative forms of sexual expression must be legitimized.

In terms of next steps, our unfinished agenda is quite large and we hope to take up part of the action agenda on power in sexual relationships emerging from this meeting. We will be moving ahead with all of our priority themes. Furthermore, we see a need to conduct additional research on "positive deviance" (although this term may not be appropriate since it connotes a problematic "negative deviance"). Finally, the Subcommittee has supported the development of practical resources, including a CD-ROM entitled "Helping Involve Men” (HIM), and a special section on a Web site devoted to men and repro- 
ductive health (www.rho.org—click on "Men and Reproductive Health"). We are also supporting the development of user-friendly protocols for men's reproductive health, such as the "Men and Reproductive Health Orientation Guide," a provider-training curriculum, and an indicators paper, to fulfill the needs of field-oriented programs.

\section{United Nations Population Fund} (UNFPA)

Below is a statement offered by

Laura Laski:

Because of ICPD and ICPD+5, when we now talk about population we mean women's sexual and reproductive health and rights, education and women's empowerment, and equality and equity. At UNFPA, we have advocated for quality reproductive health programs to serve individual needs and to ensure the right to choose. However, the reality is that sexuality and power relations are still often ignored in reproductive health programs and policies, even though they are at the core of most sexual and reproductive health problems. Now the HIV epidemic has added a sense of urgency to addressing issues of power and sexuality in UNFPA's programs.

With our new leadership, UNFPA is going through a major re-alignment process. Elements of this process include:

- Increasing our capacity to make country programs more accountable for results.
- Incorporating issues such as sexuality and power into our reproductive health agenda. Technical staff of the organization, from country support teams to headquarters, will be trained in sexuality, and programming tools are being developed to encourage country offices to support the inclusion of sexuality in reproductive health settings.

- Placing priority on adolescent girls and boys. Despite legal action to protect reproductive rights and ensure gender equality taken by many countries since Cairo, girls still lack fundamental legal protections. For example, many countries do not enforce a minimum age of marriage, which makes it very difficult to prevent not only early pregnancy but also HIV infection. Further, many countries do not recognize the concept of rape within marriage.

- Improving the quality of care. We are working in partnership with UNICEF, WHO, ILO, and other NGOs to develop a common understanding of quality of care that would increase partnership between reproductive health providers and consumers and help providers address gender power relations and sexuality.

The HIV epidemic bas added a sense of urgency to addressing issues of power and sexuality in UNFPA's programs. 
We need to be specific about the behavioral changes we are asking men to make, whether in their role as policymakers and community leaders or as husbands and fathers. UNFPA works toward increasing male support of women's reproductive health choices, and increasing their involvement in responsible parenthood and sexual and reproductive behavior, including family planning, prenatal care, maternal and child health care, prevention of STIs, and involvement in the equal care of children.

\section{Population Council}

Power in sexual relationships bas been an important area of discussion within the Population Council's regional offices over the past few years. Ayorinde Ajayi, director of the Council's East and Southern African regional program, is one of the people who bave taken up this agenda and moved it forward. Below is bis statement:

Representing the Population Council's regional offices, I will speak about the evolution of my program's work on power in sexual relationships. This is an area to which we have come relatively recently, with serious efforts being only one or two years old following a meeting on adolescents and partnership issues in early 2000.

Much of my interest in the issue derives from the fact that I live in an environment where power in sexual relationships has many negative manifesta- tions. HIV, for example, is increasingly a disease affecting teenage girls, and this phenomenon is centrally related to power dynamics. 15-19-year-old adolescent girls in Kenya are seven times as likely to have HIV than boys of the same age, and $60 \%$ of new HIV infections are within that age group. We also know that in at least $40 \%$ of the cases the first sexual intercourse of Kenyan girls 15-19 years old is coerced. This makes it very difficult for us to just sit by and say get the condoms out there. We have to be concerned about what happens with the condoms once we get them out there.

My colleagues and I decided to examine what we could do within our existing programs to deepen our understanding of the power variable. We started out with a basic set of hypotheses:

- Gender-based power imbalances in relationships constrain women in negotiating safer sex and exercising reproductive choice.

- These imbalances in power constrain women from discussing reproductive health issues with their partners.

- Reproductive health programs have a responsibility to help women address this imbalance.

With help from Julie Pulerwitz, ${ }^{15}$ we developed 12 questions to include in regional surveys. In one survey, the Frontiers Global Youth Intervention Project (a baseline study in Western Kenya funded by USAID), questions were asked

${ }^{15}$ See box on page 44 for discussion of Pulerwitz and colleagues' Sexual Relationship Power Scale. 
about discussion of contraception, desired number of children, couples' use of barrier methods, and perceptions of relative power within relationships. From the results of the study we determined that women's ability to bring up reproductive health subjects for discussion is critical and is related to their power within relationships.

Our next steps in the region include:

- Developing and validating a version of the Sexual Relationship Power Scale;

- Comparing the responses of parents with those of adolescents to see how perceived power of women within relationships is changing across generations;

- Including specific questions on consistent condom use and current relationships in the next round of field surveys (as this was left out of the first round); and

- Developing and testing interventions for improving women's relative power within relationships that can be included in intervention studies in the region.

\section{Population Council's}

Horizons Program

Below is a statement offered by

Andrew Fisher:

I will discuss current studies and future directions relating to power in sexual relationships in the Horizons Program, drawing on work by my colleagues Ellen Weiss and Julie Pulerwitz. Our perspective on power and sexual relations has three elements:
I live in an environment where power in sexual relationships bas many negative manifestations... This makes it very difficult for us to just sit by and say get the condoms out there. We bave to be concerned about what bappens with the condoms once we get them out there.

1. Gender, sexuality, power dynamics, and behavior change are cross-cutting themes that affect all aspects of HIV/AIDS.

2. These constructs are relevant worldwide but vary in intensity and effect, and are difficult to influence programmatically.

3. Before these constructs can be measured or addressed through programs, they need to be operationalized.

Findings from selected studies in Africa highlight some of the challenges involved in addressing power in sexual relationships. In Zimbabwe, we found that women believe more male involvement would improve communication and strengthen the family bond, but that discussing safer sex can lead to conflict because it implies a lack of trust. Men want to be more involved in antenatal care, but fear losing respect because pregnancy is a "woman's issue." In Nigeria, research on dual protection found that clients and service providers cited men as the main obstacles to protection against both unwanted pregnancy and sexually transmitted infection. Women acknowledge that their husbands have outside partners, and are aware of their HIV/ 


\section{Ecological model: Power is expressed at many levels and can be influenced at many levels}

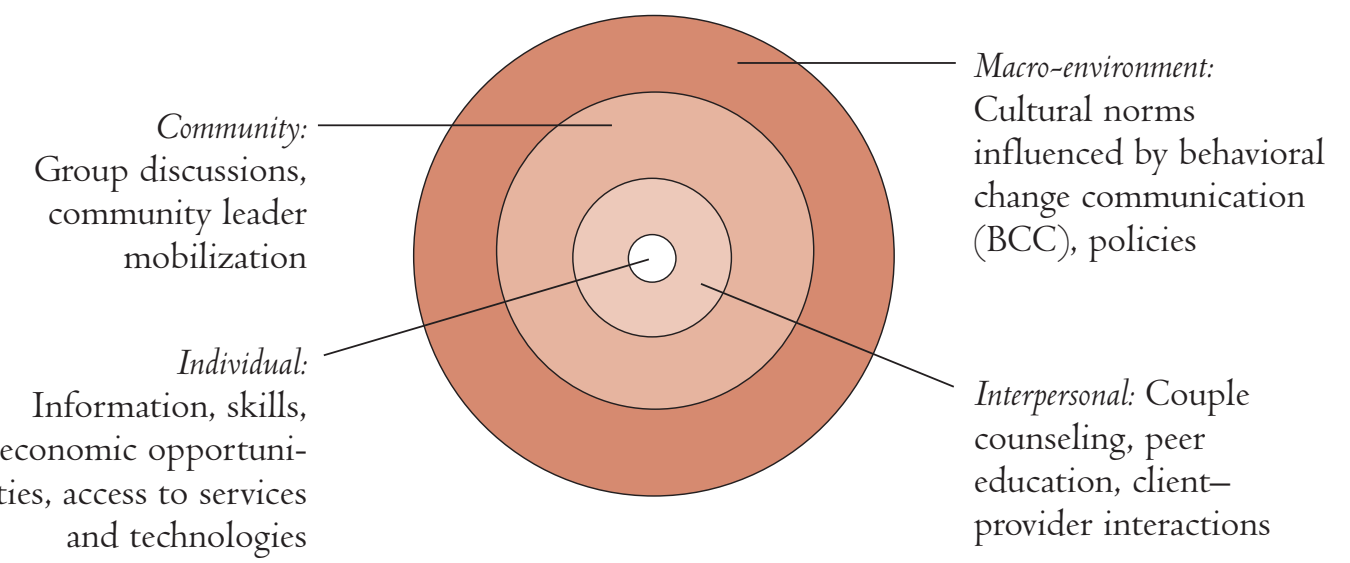

STI risk, but fear rejection, conflict, and violence if they confront their partners on the need for dual protection. In Tanzania, a recent study of HIV serostatus disclosure found that fear of partner's reaction was the major reason for non-disclosure among women. While only $5 \%$ of the women interviewed actually experienced a negative reaction to their disclosure (i.e., being blamed, abused, or abandoned), $38 \%$ had a history of partner violence.

The implications of these findings are that gender-related power dynamics are clear obstacles to couple communication, safer sex negotiation, and HIV/AIDS risk reduction. Multiple actors should be addressed, including partners, providers, and the wider community. One can see through an ecological model (see box) that power is expressed at multiple levels (the community, the interpersonal, the individual, and the macro-environment), and that each of these levels suggests different kinds of interventions.
Looking ahead, there is a need to:

- Continue couple and communitylevel interventions research (the independent variables);

- Seek to affect directly elements of power in sexual relationships (the dependent variable);

- Account for multiple levels of intervention in varied cultural settings (the intervening variables);

- Allow enough time for interventions to influence complex elements of gender and power;

- Distill our findings, disseminate them, and seek program changes.

Gender-related power dynamics are clear obstacles to couple communication, safer sex negotiation, and HIV/AIDS risk reduction. 


\section{MacArthur Foundation}

Below is a statement offered by

Carmen Barroso:

Knowledge of the links between power and sexuality has influenced MacArthur's grantmaking since we started making grants in the population area in 1986.

Power. Acknowledging the importance of power in gender relationships is a long-term process and we have taken only the first steps. There are still enormous challenges, both at the level of policies and at the level of individual behaviors and attitudes. This is particularly true of the area of male involvement. When MacArthur began making grants in this area in 1992, the dominant discourse was on "male responsibility." Programs blamed men for their reckless behavior much in the same way that women had been blamed for having too many children. The objective was also very narrow: to convince men to adopt or to support contraception. Unbalanced gender relations were not questioned, they were even reinforced. Vasectomies, for instance, were promoted as enabling men to have sex free from responsibility. MacArthur encouraged individuals and later organizations interested in helping men to develop egalitarian relationships and to create new masculinities. But still, it seems there is more interest on the part of women to get men involved than on the part of men themselves. The main reason is probably that while men may have a lot to
The major incentive to adopt responsible behaviors is

bope for the future. And that we cannot create with

localized sectoral projects. Only multisectoral policies

can reverse the macroeconomic trends generating

increased poverty.

gain from more egalitarian relationships, this may not be immediately clear. Other reasons, though, may be linked to the way programs are designed; for example, by shying away from sexuality and focusing only on reproduction, health programs do not address many of men's needs.

Sex. The major way that MacArthur has tried to address sex has been through sexuality education. We supported individuals and organizations that developed innovative methodologies to engage young people in broad discussions about the full range of issues related to pleasurable and responsible sexuality. Now our grantees are moving from the development of models to advocacy in order to convince governments to implement comprehensive, gender-sensitive sexuality education.

However, sexuality education is not enough-young people must have incentives to apply what they learn. The major incentive to adopt responsible behaviors is hope for the future. And that we cannot create with localized sectoral projects. Only multisectoral policies can reverse the macroeconomic trends generating increased poverty. 
MacArthur is aware of the limits of population grantmaking and is developing a complementary area where issues of globalization will be addressed.

MacArthur has also attempted to address other types of power imbalances in its programming. Considering the imbalanced power relationships between Northern and Southern countries, we have created in-country offices and staffed them with local nationals, giving the majority of our grants to indigenous organizations in the developing world, and supporting them in the creation of international networks. And we have tried to address power imbalances in our relationships with grantees by trying to be as transparent and accountable as possible. Finally, we have addressed gender inequalities together with other inequalities, such as those based on race and class.

MacArthur has just gone through a strategic review. In our new guidelines the most important change is a focus on prevention of maternal morbidity and mortality and promotion of sexual and reproductive health and rights of young people. But we have kept our basic conceptual framework of human rights and gender equity, and power relationships and sexuality are as relevant as ever.

\section{Ford Foundation}

Below is a statement offered by Sarab Costa: Since the early 1990s, the Ford Foundation's programs have addressed gender, sexual and reproductive choice, sex education and sexual health, and HIV/

AIDS in the context of gender relations and the broad development needs of individuals and communities. Eleven out of 14 of Ford's field offices now have Sexual and Reproductive Health programming.

Sexuality. Because we saw that sexuality was an underpinning of reproductive health, particularly of the growing HIV/AIDS epidemic, in 1994 the Foundation's board approved the incorporation of sexuality as a critical component in its reproductive health agenda. This development allowed us to promote the broader concept of sexual well-being as an underlying determinant of health outcomes as well as a desirable goal in and of itself. Ford supports research as well as training programs on sexuality. Programs explore how sexuality and patterns of sexual health are defined, conducted, and represented cross-culturally, and examine how sexual behaviors contribute to reproductive health and sexual problems. Our activities also focus on comprehensive sexuality education and youth-friendly services. We are currently undertaking a global assessment of our work on sexuality, with a view to trying to define future strategies for scaling up this work.

Empowerment. Another of Ford's primary concerns has been focusing on the empowerment of women. In the mid1990s we concluded that improvements in women's reproductive health depended on complementary advancements in 
women's status in society as well as within their communities and families. As a result, the Foundation increased its attention to gender-oriented work that included men and challenged gender inequalities.

Restructuring the Foundation. Restructuring of the Foundation in 1997 resulted in incorporating sexual and reproductive health into the new Assets Building/ Community Development Program on the premise that reproductive health affects people's capacity to work and lead satisfying lives. It also shapes their ability to build strong interpersonal and intergenerational relationships based on gender equality, and to acquire the knowledge and skills necessary to bring about changes in their social, community, legal, and political environments. The program has begun to address more directly the broad-based social and economic conditions underlying gender inequality and gender dynamics in sexual relationships. While the Foundation's comprehensive approach demonstrates the need for intersectoral coordination and programs, finding ways to initiate and maintain these links poses additional challenges. We are currently assessing different strategies linking reproductive health behaviors to economic behavior at the practical level in a number of countries, including India, Kenya, and Nigeria, and are also working on indicators to assess this work more efficiently.

During the past ten years our approach has broadened significantly,
We bave looked at the opportunities and challenges presented by placing sexual and reproductive bealth as a vital buman and social asset within a broader development agenda aimed at reducing poverty and injustice.

and we have looked at the opportunities and challenges presented by placing sexual and reproductive health as a vital human and social asset within a broader development agenda aimed at reducing poverty and injustice. Over the next ten years the overall goal of Ford Foundation sexual and reproductive health programming is to assist individuals, families, and communities in obtaining the conditions necessary for positive health outcomes. Those conditions include healthy pleasurable sexuality, equitable gender relations, reproductive choice, social networks, and knowledge and skills. Among the strategies for achieving this objective are:

- Sustaining and maintaining an inclusive definition and approach to sexual and reproductive health within development agendas;

- Promoting gender-sensitive and clientfocused sexual and reproductive health care within fragile health sectors; and

- Strengthening local capacity by identifying avenues for building the range of human and social conditions necessary for sustaining health. 
United States Agency for

International Development (USAID), HIV / AIDS Division

Below is a statement offered by Paul Delay:

I would like to show the group some overwhelming data on HIV transmission dynamics in sub-Saharan Africa that highlight girls' gender-based vulnerability. These data illustrate that what we are dealing with is essentially a girls' epidemic driven by male behavior; males are about ten years behind in terms of infection and death (see figure). AIDS affects females long before they seek family planning services or methods (a ten-year disconnect), which poses a great challenge for how to structure programs. For example, by the time a woman gets to a family planning clinic in Kenya, it may already be too late to prevent her from becoming infected. In fact, nearly $80 \%$ of those women who will become infected over their lifetime are already infected at that point in time.
Finding a way to take an understanding of power and gender to girls is thus absolutely critical. I will outline here the evolution of USAID's gender mandate and the challenges my colleagues and I face in trying to work on gender and power within an agency like USAID.

After the Cairo and Beijing conferences, in 1996 USAID passed the Gender Plan of Action to push ahead its women in development agenda. More recently, it has mandated that gender constraints be addressed in USAID's programming by passing new guidelines for the inclusion of gender issues in the Agency's program design and procurement process. As explained earlier by Sam Clark, the Interagency Gender Working Group (IGWG) was established in 1997.

Despite this hard work, however, difficult questions remain. I will outline four interrelated challenges we face in trying to work with gender and power:

HIV PREVALENCE (\%) FOR PREGNANT WOMEN 1996 AND GENERAL POPULATION 1995-1996, URBAN CENTER OF ZAMBIA

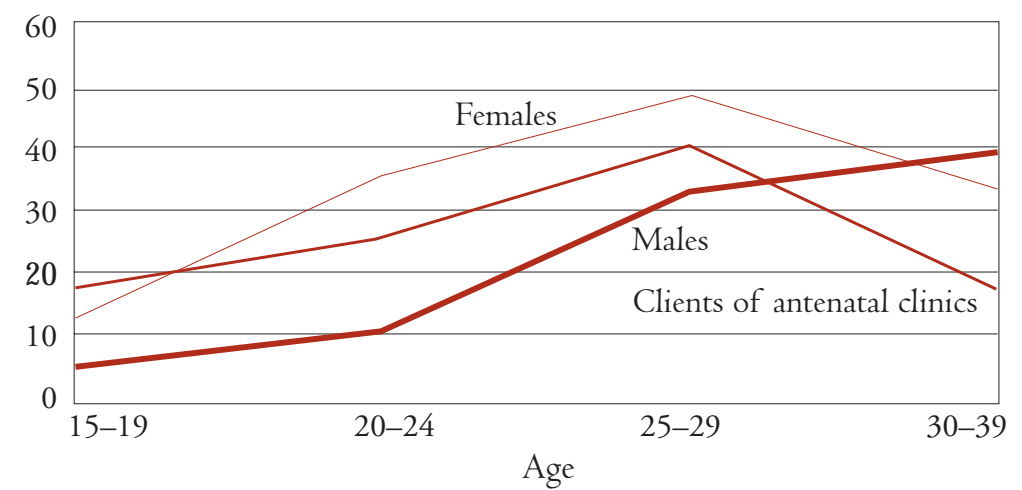

Source: K. Fylkesnes et al. 1998. "Studying dynamics of the HIV epidemic: Population-based data compared with sentinel surveillance in Zambia," AIDS 12(10): 1227-1234. 
1. Interpreting results of biomedical and traditional behavior change models. Ten years ago our approaches were fairly biomedical and focused on standard behavior change models and STI treatment. Then, in the mid-1990s, when numbers of new infections were exploding and nothing seemed to be working, there was a swing into the socioeconomic determinants of vulnerability such as gender inequity and poverty. However, when success stories began to emerge in 1996, 1997, and 1998 in countries such as Thailand and Uganda, a backing away from socioeconomic determinants of vulnerability began because the more biomedical behavior change interventions did seem to be working in some settings. We are currently somewhere in limbo between focusing on the underlying causes of vulnerability and the more direct technical interventions.

2. Providing evidence of the "value added" of gender-sensitive programs. We must better represent how an understanding of gender and power can help us in our interventions, and what interventions can actually be done. Two examples of areas of work on HIV/AIDS where gender and power are major deciding factors in the success of interventions are voluntary counseling and testing and mother-to-child transmission interventions. There have been major failures with such interventions in many parts of the world because women will not elect
The HIV transmission dynamics in sub-Sabaran Africa illustrate that what we are dealing with is essentially a girls' epidemic driven by male behavior; males are about ten years bebind in terms of infection and death.

to be screened, to receive the test results, to take them back to the family, and then to receive the therapies.

3. Measuring a change in power relations. As an agency, USAID is under pressure to demonstrate results in order to sustain its program at a particular funding level. The challenge is in identifying appropriate tools that can measure a change not only in power relations but also in HIV transmission or use of family planning. Such changes are gradual and difficult to capture.

4. The bias against gender-sensitive and "women's empowerment" programs. There is a perception that gender and women's empowerment can represent a left-wing, feminist agenda. We must find a way to make these concepts more palatable and less polarizing.

My suggestions for moving forward all require the help of those present:

- Proving that gender empowerment is the missing link to improving use of family planning and reducing HIV transmission; 
- Developing clear guidelines and tools to enable our projects and programs in the field to address gender inequities; and

- Being more politically sophisticated in the language we use and the arguments we make to assure buy-in. We must present our issues in a way that will resonate with those who have the discretion over our funding.

\section{Discussion}

One participant argued that to the extent that we have a model of sexual partnerships it assumes they have been safe and voluntary. In fact a high proportion are coerced, and certainly not safe, and we must address that fact in our programs.

Another posited that within unequal power relationships women use covert forms of power and coping mechanisms. Quiet women may just be letting men blow off steam, while those who talk a lot may bear the brunt of violence. And speaking from her experience working with battered women, another participant noted that many women are not ready to leave their abusive husbands because in fact they have strong emotional ties to the men beating them. She argued that we could put women's relationships at risk when women do not want them to terminate.

Finally, another echoed earlier dialogue by lamenting the difficulty of keeping sexuality in view in these discussions of sexual relationships. The consequence, she said, is working with a reproductive model with sexuality added on, limiting the purview to heterosexual couples and ignoring insights from revolutionary work on sexuality over the past 20 years. The commentator observed, "It seems sexuality is like a balloon that flies away." 


\section{LOOKING TO THE FUTURE: W ORKING GROUPS}

The participants divided into three working groups for the last session: Methodologies for Research and Evaluation, Service-delivery Interventions, and Community and Media Interventions. The purpose of these groups, which people joined according to interest, was to allow discussion of various topics in greater detail. It was also the point in the meeting to explicitly look toward future directions in our work. Each group was asked to come up with two to three recommendations for immediate action, and two to three longer-term goals.

\section{Working group \#1: Methodologies} for research and evaluation

Julie Pulerwitz of PATH and Ellen Weiss of the International Center for Research on Women led the largest of the groups in a discussion of methodological issues. The group began by discussing the applicability of the power construct across cultures given the different ways power and sexuality are expressed. Some believed that all measures need to be locally developed. Others noted the usefulness of a combination of universal measures that would permit comparison across studies together with locally specific measures. Participants underscored the importance of qualitative research for developing valid measures in terms of construct validity (e.g., that you are measuring what you want to measure) and content validity (e.g., that all relevant subdomains are covered). Valid measures are essential for proving that changes in power $d y$ namics have a positive effect on reproductive health outcomes. Many in the group also recommended that women's control of their sexuality be an important outcome to be measured. To demonstrate the predictive ability of power to influence reproductive health and sexuality outcomes, longitudinal studies are needed. Moreover, multi-level analyses are needed to document changes in power dynamics at the individual, couple, and community levels. A final point to emerge was that intervention research to measure changes in power dynamics must allow for extensive community involvement.

Immediately actionable items included:

- Identify examples of measures, particularly indexes and scales, that have been used to measure individual and relational power.

- Initiate studies to validate measures of power in different contexts.

- Involve NGOs focused on gender when conducting research to examine power and sexuality.

Longer-terms goals included:

- Conduct longitudinal intervention studies, including those that focus on structural issues, to examine changes in power dynamics at the individual, couple, and community levels over time. 
- Develop and test indicators of institutional and community change that may occur as a result of changes in individual and relational power.

- Advocate for longer-term funding by donors for intervention research focused on changing power dynamics.
Working group \#2:

Service-delivery interventions

Elaine Murphy of PATH and Martha

Brady of the Population Council facili-

tated the discussion of service-delivery interventions. The group recognized the need for a multi-sectoral approach to

\section{The Sexual Relationship Power Scale}

A RECENT METHOdOLOGical adVAnCE, cited numerous times throughout the meeting, was the development of a Sexual Relationship Power Scale (SRPS) by Pulerwitz and colleagues. The SRPS was developed to assess power in intimate relationships. The 23-item scale, with items scored on a 4-point Likert scale, can be divided into two subscales. The subscales concern two conceptual dimensions of relationship power: (1) Decisionmaking Dominance; and (2) Relationship Control. The subscales can be used separately or combined, depending upon research requirements. The Decisionmaking Dominance subscale contains questions on who has more say in various decisions (e.g., "My partner usually has more say about whether we have sex"), and the Relationship Control subscale contains questions about the nature of the relationship (e.g., "Most of the time, we do what my partner wants to do”).

Two equivalent versions of the SRPS were developed, one in English and one in Spanish. Items were designed by combining a theoretical perspective that explicitly addresses gender and power and via focus group discussions with Latina and African-American women in the United States. Items incorporate events common to both married and dating couples, and address both sexual power and power in other areas of an intimate relationship.

The SRPS was found to be internally consistent. As part of the original psychometric evaluation of the SRPS, additional data were collected from study subjects on physical abuse and forced sex in their current relationship, condom use, relationship satisfaction, and a variety of sociodemographic variables. As predicted, a relationship history of physical violence and forced sex was negatively correlated with the SRPS. Consistent condom use, a higher education level, and relationship satisfaction were positively correlated with the SRPS.

The Sexual Relationship Power Scale has been used or adapted for other populations in Kenya, Zimbabwe, the United States, and Mexico.

For a more in-depth discussion of this scale, refer to Julie Pulerwitz, Steven L. Gortmaker, and William Dejong. 2000. "Measuring sexual relationship power in HIV/STD research," Sex Roles 42(7): 637-660. 
address issues of gender inequity more comprehensively, yet noted that significant contributions are possible within the health sector. For example, numerous opportunities for improvement exist at all levels of service and within a range of health care systems. The group discussed the need for experimentation with new service-delivery models that go beyond traditional clinical settings. They suggested more concentrated efforts at the community level.

Immediately actionable items included:

- Redefine "quality" to include discussion of power imbalances between sexual partners and their influence on reproductive health decisionmaking.

- Change the standard of care to reflect this power imbalance by improving/expanding the content of provider training, refining service protocols where applicable, and developing new and improved tools and indicators for evaluating services.

- Develop an inventory of potential entry points for appropriately involving men as supportive partners, including but not limited to "couplefriendly" services.

- Explore ways to reach out to the various segments of the "youth population" while recognizing gender power differentials between males and females.

- Experiment with links between reproductive health and income generation for adolescent girls and adult women.
- Design and test interventions aimed at drawing in first-time fathers.

Longer-term goals included:

- Design reproductive health services to meet the needs of women exposed to sexual trafficking.

- Carry out gender awareness activities with children aged $6-10$, in recognition of the fact that the socialization of young children has a formative role in their understanding and perception of gender norms and roles.

- Endeavor to make health services sensitive to the specific needs of gay and bisexual people in selected settings.

The group mentioned USAID's Maximizing Access and Quality (MAQ) initiative and the Interagency Gender Working Group's Men and Reproductive Health Subcommittee as two existing interagency mechanisms that might be used to effect a minimum recognition of power issues in highquality provider-client exchanges.

\section{Working group \#3: Community} and media interventions

This group, facilitated by Ronnie Lovich of Save the Children and Nancy Yinger of the Population Reference Bureau, spent much time discussing the links between community and media. Group members identified three immediately actionable activities:

- Carry out retrospective assessments to see the evolution of programs. 
- Help sponsor media networks linking journalists with researchers, the community, and policymakers.

- Conduct trainings for each other on how to discuss issues of sexuality, because even the participants in this meeting have difficulty discussing these issues.

Longer-term goals included:

- Come to some agreement on the definition and parameters of sexuality, and expand the discussion.

- Link social equity and gender equity, recognizing that if men see power as a zero-sum game we must find ways of articulating what is in it for them. Looking at ways men are disempowered by poverty, unemployment, and lack of education, and linking these issues to gender inequities may be a way of engaging them.

- Establish the use of group self-diagnosis and participatory learning and action as a regular practice in community-level work. A need was recognized to expand techniques for going into the community, listening to people, understanding their perceptions of their needs, recognizing the knowledge that they already have, facilitating dialogue, and then mobilizing community action for change.

\section{Discussion}

A number of participants commented that going through the process of listening to community members can serve to debunk many of the assumptions that those who are urban and educated may have about community norms. Gathering community members together to talk about norms can also provide opportunities for communities to see how much they really do know about what other members are thinking. Barbara Ibrahim of the Population Council, the chair of the session, reported on town meetings in Egypt that provided a chance for communities to reassess their practices and values related to female genital mutilation and see whether they were still serving community interests. The resistance to those discussions anticipated by development workers never materialized.

The question of articulating how men can gain from change was addressed by several participants. One participant said that there are now several studies asking men how they feel about prevailing gender norms. To the surprise of many, respondents said that they found the norms constricting, like a straitjacket. So one way to think about "what is in it for men" is that they will have an opportunity to take the straitjacket off. Another participant suggested that men are more likely to perceive benefits of changed gender norms in their roles as fathers: in the desire for safer families, for child survival, and for preventing harm to one's daughter. Finally, another suggested that we are forgetting that men are in the same community as women; they may personally gain from 
more sexual intimacy and more egalitarian relationships.

Another participant raised the issue that other family members may feel they are losing in patriarchal societies where a strong sexual bond between couples can be threatening to the power of others in the family. For a man to break with existing norms, he must be willing to stand up to family and community pressures. This emphasizes the importance of working at many different levels, and engaging important gatekeepers as well as couples. 


\section{CLOSING REMARKS}

Judith Bruce of the Population Council closed the meeting with a summary of the themes that emerged throughout the course of the two days and some issues to bear in mind for the future.

Bruce began by saying that virtually every presentation and observation acknowledged that women and men both have a great deal to gain from a change, at the individual level, in dynamics within partnerships, and at the level of the family. At the community level, the gains from adjusting imbalances in power in sexual relationships are now viewed with much greater consensus as contributing positively, indeed crucially, to our ability to contain the HIV/AIDS epidemic; foster effective, safe, and chosen fertility regulation; reduce maternal mortality; and improve child health.

Our ability to measure change is still limited. Our ability to link changes in communication patterns between couples and purported reductions in imbalances in power to valued outcomes is similarly limited. However, for the time being we cannot afford the luxury of sequentially developing perfect measures before acting. Even in the absence of the proofs we may need, we have a mandate to intervene. International consensus documents have validated a whole series of sexual and reproductive human rights, including the right to have knowledge about our bodies, control

\section{Virtually every presentation and observation acknowledged that women and men both bave a great deal to gain from a change.}

over our sexual lives, and to have the knowledge-if not always the negotiating means-to protect our health. Bruce posited that over the short term the emphasis on the rights dimension of this work may help maintain our momentum until we fine-tune the social science and anthropological measurement skills that underpin our work.

Throughout the meeting, concerns were expressed as to how to make the gender and power dialogue more inclusive, embracing a more diverse spectrum of sexual and behavioral needs. Bruce acknowledged that this meeting in its design dealt mainly with heterosexual relationships, and that we are still far from crossing that boundary. Sexuality is a new topic, and we must press to define it beyond our perceptions of traditional male/female relationships.

Finally, Bruce listed her own view of desirable next steps:

- Include information about the potential impact of sexual partnership dynamics in the standard information that is exchanged between 
client and provider. It is not merely sufficient, for example, in a family planning service, to inform individuals about a method's narrow technicalities and side effects. Information exchange in the age of HIV and AIDS, and in light of all we know about coercion and violence in sexual partnerships, must acknowledge clients as part of sexually active couples. Individuals need to know that their own sexual behavior and that of their partner (or partners) often bear heavily on their own health and on the acceptability, safety, and likely effectiveness of the technologies offered to them.

- We must go public about power, fostering community-level dialogue that makes visible in the public domain what has been too long considered private. It is important to acknowledge that many sexual contacts are not fully voluntary, safe, or pleasurable. "Sex" is not the dirty word so much as "power" is.

- Instill an understanding of power relationships between intimate partners into the conventional service-delivery systems-particularly maternal and child health. Some of the most sensitive implications of an imbalance of power in sexual relationships may be more readily accepted, paradoxically, in these traditional settings, where, for example, the maternal-to-child transmission of AIDS can open a discussion with male partners about protecting their wives/the mothers of their children. While moving a discussion of power in sexual relationships into the wider community is absolutely vital, it is also important, in Bruce's words, "to revisit some of these dusty old infrastructures and try to tune them up."

- In exploring the meaning of power in sexual relationships for adolescents, we must craft our messages to take account of age, gender, marital status, and fertility intention. The possibility for voluntary and informed sexual relations on the part of an unmarried adolescent girl in a relationship with a boy near her age is quite different from a young adolescent married to a man many years older and under pressure to become pregnant.

- Finally, acknowledging the tight link, particularly for women, between improving health outcomes and social and economic change, programs must find functional and flexible ways to support "integration." For example, projects should be allowed real community-based diagnostic phases, reserving some of their decisions-and their fundsfor potentially non-reproductive health interventions (such as literacy classes, savings clubs, and other closely related and often vital empowerment strategies). Flexibility of funding must be matched by commitment to the longer term, because many of the changes we are 
seeking will be impossible to render or view over a short time frame, particularly when working with young people. And it will be crucial in our search for appropriate measures to define intermediate changes, such as more dialogue between couples, that are goods in and of themselves. 


\section{APPENDIX: MEETING PARTICIPANTS}

\author{
Robert Ainslie \\ Johns Hopkins University Center for \\ Communication Programs \\ rainslie@jhuccp.org \\ Ayorinde Ajayi \\ Population Council, Kenya \\ aajayi@popcouncil.or.ke \\ Hemant Apte \\ KEM Hospital and Research Centre \\ ham@pn2.vsnl.net.in \\ Humberto Arango \\ International Planned Parenthood \\ Federation/WHR (IPPF/WHR) \\ harango@ippfwhr.org \\ Michal Avni \\ USAID \\ mavni@usaid.gov \\ Carmen Barroso \\ MacArthur Foundation \\ cbarroso@macfound.org \\ Julie Becker \\ EngenderHealth \\ jbecker@engenderhealth.org \\ Robert Becker \\ Planned Parenthood of New York City \\ robert.becker@ppnyc.org \\ Stan Becker \\ Johns Hopkins School of Public Health \\ sbecker@jhsph.edu \\ Sandra Bjegovic \\ Population Council \\ sbjegovic@popcouncil.org \\ Ann Blanc \\ Blancroft Research International \\ ablanc@home.com \\ Susan Bloodworth \\ PATH, D.C. \\ sbloodworth@path-dc.org
}

\author{
Lisa Bohmer \\ Pacific Institute for Women's Health \\ lbohmer@piwh.org \\ Summer Boslaugh \\ Moriah Fund \\ sboslaugh@moriahfund.org \\ Martha Brady \\ Population Council \\ mbrady@popcouncil.org \\ Sarah Braunstein \\ Population Council \\ sbraunstein@popcouncil.org \\ Judith Bruce \\ Population Council \\ jbruce@popcouncil.org \\ Michele Burger \\ Consultant \\ mburger11@aol.com \\ Lucella Campbell \\ IPPF/WHR \\ lcampbell@ippfwhr.org \\ John Casterline \\ Population Council \\ jcasterline@popcouncil.org \\ Chris Castle \\ Population Council, D.C. \\ ccastle@pcdc.org \\ Jennifer Catino \\ Population Council, Mexico \\ jcatino@popcouncil.org.mx \\ Margarita Cereijido \\ Washington Psychoanalytic Institute \\ mrcereijid@aol.com \\ Amy Charney \\ Centre for Development and \\ Population Activities \\ acharney@cedpa.org
}




\author{
Erica Chong \\ Population Council \\ echong@popcouncil.org \\ Sam Clark \\ PATH, D.C. \\ sclark@path-dc.org \\ Sarah Costa \\ Ford Foundation \\ s.costa@fordfound.org \\ Jane Cottingham \\ World Health Organization \\ cottinghamj@who.ch \\ Caroline Crosbie \\ Pathfinder International \\ ccrosbie@pathfind.org \\ Benno de Keijzer \\ Salud y Género \\ salygen@infosel.net.mx \\ Paul Delay \\ USAID \\ pdelay@usaid.gov \\ Judith Diers \\ Population Council \\ jdiers@popcouncil.org \\ Paul Dover \\ Uppsala University \\ Paul.Dover@antro.uu.se \\ Anne Dykstra \\ USAID \\ adykstra@usaid.gov \\ Nabila El-Bassel \\ Columbia University School of Social Work \\ ne5@columbia.edu \\ Julia Ernst \\ Center for Reproductive Law and Policy \\ julia.ernst@crlp.org \\ Marguerite Farrell \\ USAID \\ mfarrell@usaid.gov
}

\author{
Andrew Fisher \\ Population Council, D.C. \\ afisher@pcdc.org \\ Lynn Freedman \\ Center for Population and Family Health \\ lpf1@columbia.edu \\ Victoria Frye \\ Center for Health and Gender Equity \\ vfrye@genderhealth.org \\ Susana Galdos \\ Movimiento Manuela Ramos \\ sgaldos@manuela.org.pe \\ Susan Gibbs \\ Summit Foundation \\ sgibbs@summitfdn.org \\ Belkis Giorgis \\ Academy for Educational Development \\ bgiorgis@aed.org \\ Françoise Girard \\ International Women's Health Coalition \\ francoise@iwhc.org \\ Rachel Goldberg \\ Population Council \\ rgoldberg@popcouncil.org \\ Michelle Gray \\ Population Council, D.C. \\ mgray@pcdc.org \\ Margaret Greene \\ Population Action International \\ mgreene@popact.org \\ Alan Greig \\ Consultant \\ alangreig@earthlink.net \\ Jay Gribble \\ Georgetown University \\ jng@georgetown.edu \\ Alessandra Guedes \\ IPPF/WHR \\ aguedes@ippfwhr.org
}


Geeta Rao Gupta

International Center for Research on Women geeta@icrw.org

Sarah Harbison

USAID

sharbison@usaid.gov

Tanya Harrel

SYNERGY Project

tanya@tvtassociates.com

Sarah Hawkes

Population Council, India

sarah@pcindia.org

Judith F. Helzner

IPPF/WHR

jhelzner@ippfwhr.org

Jennifer Hirsch

Rollins School of Public Health

jshirsc@sph.emory.edu

Susie Hoffman

HIV Center for Clinical and Behavioral Studies

hoffman@pi.cpmc.columbia.edu

Dale Huntington

Population Council, India

dhuntington@pcindia.org

Barbara Ibrahim

Population Council, Egypt

bibrahim@pccairo.org

Jodi Jacobson

Center for Health and Gender Equity

jjacobson@genderhealth.org

Anrudh Jain

Population Council

ajain@popcouncil.org

Carol Jenkins

National Institutes of Health

cjenkins@niaid.nih.gov

Inoussa Kaboré

Tulane University

ikabore@tulane.edu
Debra Kalmuss

Center for Population and Family Health

dk6@columbia.edu

Mihira Karra

USAID

mkarra@usaid.gov

Tabitha Keener

USAID

tkeener@usaid.gov

Sunita Kishor

MEASURE DHS+, Macro International

kishor@macroint.com

Peggy Koniz-Booher

University Research Co., LLC

pkoniz_booher@urc-chs.com

Kathleen Kurz

International Center for Research on Women

kkurz@icrw.org

Ana Langer

Population Council, Mexico

alanger@popcouncil.org.mx

Laura Laski

UNFPA

laski@unfpa.org

Ann Leonard

Population Council

aleonard1@nyc.rr.com

Laurie Liskin

Johns Hopkins University Center for

Communication Programs

1liskin@jhuccp.org

Ronnie Lovich

Save the Children

rlovich@savechildren.org

Rebecka Lundgren

Georgetown University

lundgrer@gunet.georgetown.edu

Marjorie Macieira

Summit Foundation

mmacieira@summitfdn.org 


\author{
Kerry MacQuarrie \\ International Center for Research on Women \\ kerry@icrw.org \\ Purnima Mane \\ Population Council \\ pmane@popcouncil.org \\ Amanda Martin \\ Summit Foundation \\ amartin@summitfdn.org \\ Rabia Mathai \\ American Red Cross \\ mathair@usa.redcross.org \\ Donna McCarraher \\ Family Health International \\ dmccarraher@fhi.org \\ Ann McCauley \\ Horizons Program/International Center for \\ Research on Women \\ amccauley@pcdc.org \\ Michael McGee \\ Planned Parenthood Federation of America \\ mike.mcgee@ppfa.org \\ Therese McGinn \\ Center for Population and Family Health \\ tjm22@columbia.edu \\ Oma McLaughlin \\ Centre for Development and Population Activities \\ omclaughlin@cedpa.org \\ Carey Meyers \\ Population Council \\ cmeyers@popcouncil.org \\ Alice Miller \\ Center for Population and Family Health \\ am808@columbia.edu \\ Suellen Miller \\ Population Council \\ smiller@popcouncil.org \\ Luis Mora \\ UNFPA \\ luis.mora@eat.org.mx
}

\author{
Esther Muia \\ Population Council, Kenya \\ emuia@popcouncil.or.ke \\ Elaine Murphy \\ PATH, D.C. \\ emurphy@path-dc.org \\ Margaret Neuse \\ USAID \\ mneuse@usaid.gov \\ Susan Newcomer \\ National Institute of Child Health and Human \\ Development \\ newcomes@exchange.nih.gov \\ Constance Newman \\ PRIME Project \\ cnewman@intrah.org \\ Glenn Northern \\ Planned Parenthood Federation of America \\ glenn.northern@ppfa.org \\ Maureen Norton \\ USAID \\ mnorton@usaid.gov \\ Sia Nowrojee \\ Center for Health and Gender Equity \\ snowrojee@genderhealth.org \\ Tonya Nyagiro \\ United Nations Foundation \\ tnyagiro@unfoundation.org \\ Laura Nyblade \\ International Center for Research on Women \\ lnyblade@icrw.org \\ Waafas Ofosu-Amaah \\ World Bank \\ wofosuamaah@worldbank.org \\ Naana Otto-Oyotey \\ IPPF/Global Advocacy Division \\ nottooyotey@ippf.org \\ Emma Ottolenghi \\ Population Council, D.C. \\ eottolenghi@pcdc.org
}


Saroj Pachauri

Population Council, India

monica@pcindia.org

Susan Palmore

Advance Africa

spalmore@advanceafrica.org

Rohini Pande

International Center for Research on Women

rpande@icrw.org

Richard Parker

Columbia School of Public Health

rgp11@columbia.edu

Angela Pattatucci-Aragon

National Institutes of Health

pattatua@csr.nih.gov

Wayne Pawlowski

Planned Parenthood Federation of America

wayne.pawlowski@ppfa.org

Suzanne Petroni

US Department of State

s.petroni@state.gov

Patricia Poppe

Johns Hopkins University Center for

Communication Programs

ppoppe@jhuccp.org

Julie Pulerwitz

Horizons Program/PATH

jpulerwitz@pcdc.org

Estelle Quain

USAID

equain@usaid.gov

Jewel Quallo-Rosberg

Belize Family Life Association

bfla@btl.net

Rebeca Quiroga

PATH, D.C.

rquiroga@path-dc.org

Saumya RamaRao

Population Council

sramarao@popcouncil.org
May Rihani

Academy for Educational Development

mrihani@aed.org

Karin Ringheim

PATH, D.C.

kringheim@path-dc.org

Kim Rivers

University of London

rkkstcp@ioe.ac.uk

Naomi Rutenberg

Population Council, D.C.

nrutenberg@pcdc.org

Diana Santillan

Empowerment of Women Research Program

dsantill@jsi.com

Shira Saperstein

Moriah Fund

ssaperst@moriahfund.org

Zeba Sathar

Population Council, Pakistan

zsathar@pcpak.org

Sid Schuler

JSI Research and Training Institute

sid_schuler@jsi.com

Audrey Seger

USAID

aseger@usaid.gov

Myrna Seidman

Georgetown University

seidmanm@gunet.georgetown.edu

Susheela Singh

Alan Guttmacher Institute

ssingh@agi-usa.org

Jeff Spieler

USAID

jspieler@usaid.gov

Lovisa Stannow

Pacific Institute for Women's Health

1stannow@piwh.org 
Kellie Stewart

USAID

kestewart@usaid.gov

Lindsay Stewart

Pathfinder International

1stewart@pathfind.org

John Townsend

Population Council, D.C.

jtownsend@pcdc.org

Marcia Townsend

CATALYST

mtownsend@rhcatalyst.org

Soraya Tremayne

Oxford University

soraya.tremayne@anthro.ox.ac.uk

Stephanie Urdang

UNIFEM

stephanie.urdang@undp.org

Janneke van de Wijgert

Population Council

jvandewijgert@popcouncil.org
Carole Vance

Columbia University

csv1@columbia.edu

Mary Nell Wegner

EngenderHealth

mnwegner@engenderhealth.org

Ellen Weiss

Horizons Program/International Center for

Research on Women

eweiss@pcdc.org

Amy Weissman

Save the Children

aweissman@savechildren.org

Goran Wimmerstrom

Consultant

wimmerstrom@swipnet.se

Nancy Yinger

Population Reference Bureau

nyinger@prb.org 
(P) Population Council

One Dag Hammarskjold Plaza New York, New York 10017

telephone: 001 212-339-0500

fax: 001 212-755-6052

e-mail: pubinfo@popcouncil.org www.popcouncil.org

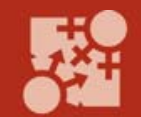

\section{IGWG}

United States Agency for International Development 1300 Pennsylvania Avenue, NW

G/PHN/POP/PE3.6.142B

Washington, DC 20523

telephone: 001 202-712-0662

fax: 001 202-216-3046

e-mail: IGWG@usaid.gov 